\title{
Engineering Analysis Of Intermediate Loop And Process Heat Exchanger Requirements To Include Configuration Analysis And Materials Needs
}

T. M. Lillo

R. L. Williamson

T. R. Reed

C. B. Davis

D. M. Ginosar

September 2005

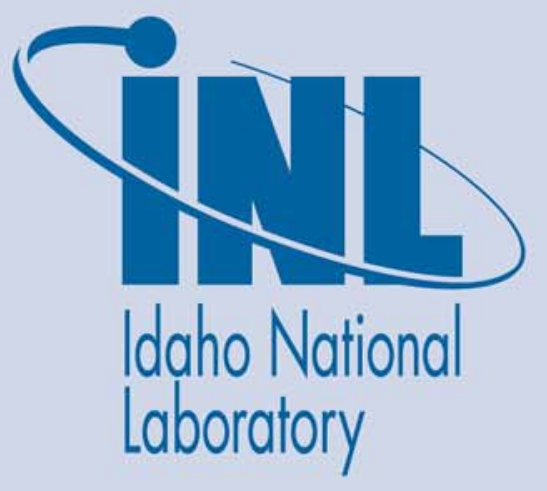

The INL is a U.S. Department of Energy National Laboratory operated by Battelle Energy Alliance 



\title{
Engineering Analysis of Intermediate Loop and Process Heat Exchanger Requirements to Include Configuration Analysis and Materials Needs
}

\author{
T. M. Lillo, R. L. Williamson, T.R. Reed, C. B. Davis, D.M. Ginosar
}

September 2005

Idaho National Laboratory

Idaho Falls, Idaho 83415

Prepared for the

U.S. Department of Energy

Assistant Secretary for Nuclear Energy

Under DOE Idaho Operations Office

Contract DE-AC07-05ID14517 


\section{ABSTRACT}

The need to locate advanced hydrogen production facilities a finite distance away from a nuclear power source necessitates the need for an intermediate heat transport loop (IHTL). This IHTL must not only efficiently transport energy over distances up to 500 meters but must also be capable of operating at high temperatures $\left(\geq 850^{\circ} \mathrm{C}\right)$ for many years. High temperature, long term operation raises concerns of material strength, creep resistance and general material stability (corrosion resistance). IHTL design is currently in the initial stages. Many questions remain to be answered before intelligent design can begin.

The report begins to look at some of the issues surrounding the main components of an IHTL. Specifically, a stress analysis of a compact heat exchanger design under expected operating conditions is reported. Also the results of a thermal analysis performed on two IHTL pipe configurations for different heat transport fluids are presented. The configurations consist of separate hot supply and cold return legs as well as annular design in which the hot fluid is carried in an inner pipe and the cold return fluids travels in the opposite direction in the annular space around the hot pipe. The effects of insulation configurations on pipe configuration performance are also reported.

Finally, a simple analysis of two different process heat exchanger designs, one a tube in shell type and the other a compact or microchannel reactor are evaluated in light of catalyst requirements.

Important insights into the critical areas of research and development are gained from these analyses, guiding the direction of future areas of research. 


\section{CONTENTS}

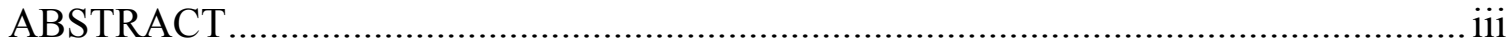

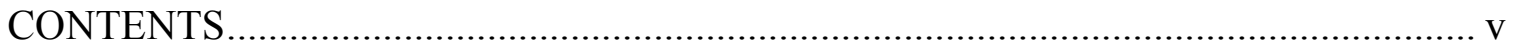

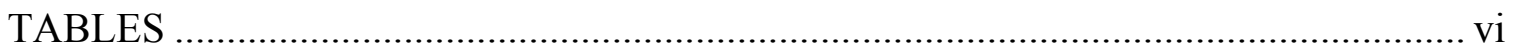

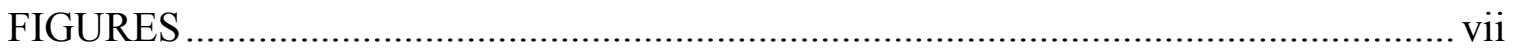

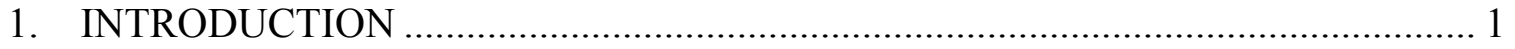

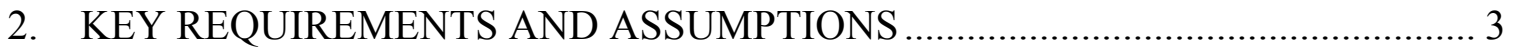

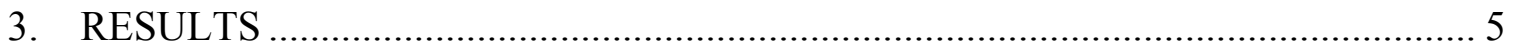

3.1 Intermediate Heat Exchanger Stress Analysis ................................................... 5

3.2 Thermal Analysis of the IHTL Pipe Configuration .......................................... 15

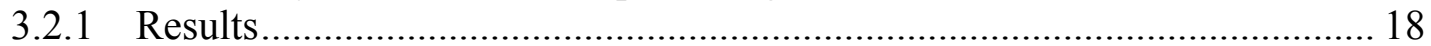

3.3 Process Heat Exchanger Analysis.................................................................... 25

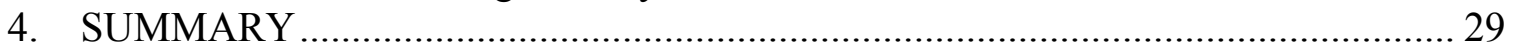

4.1 Intermediate Heat Exchanger Stress Analysis ............................................... 29

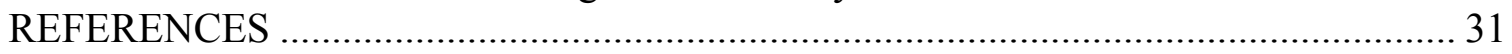

Appendix A. Thermal Analysis of Separate Hot/Cold Pipe Design ................................ 33

Appendix B. Thermal Analysis of the Annular Heat Transport Design.......................... 37

Appendix C. Parameters Used in the Thermal Analysis.................................................. 41 


\section{TABLES}

Table 3-1. Summary of the stress calculations for the IHX......................................... 6

Table 3-2. Summary of the stress calculations for the IHTL piping ............................ 16

Table 3-3. Temperature Change for the Separate Leg Pipe Configuration ..................... 19

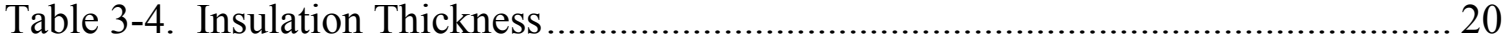

Table 3-5. Effect of Hot Pipe Insulation Configuration on Pipe Temperatures* ............ 23

Table 3-6. Comparison of Pipe Configurations ........................................................... 24

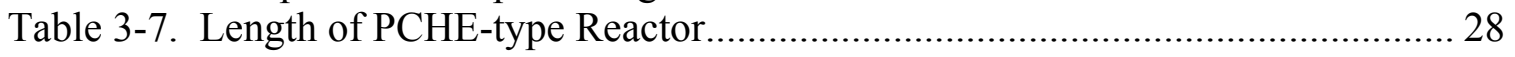




\section{FIGURES}

Figure 2-1. Direct electrical cycle and serial IHX (Configuration 1) .............................. 3

Figure 3-1. Diffusion bonded layers in a Heatric heat exchanger .................................... 5

Figure 3-2. Flow channel cross section in Heatric diffusion-bonded heat exchanger....... 6

Figure 3-3. Illustration of the IHX channel configuration and definition of the parameters

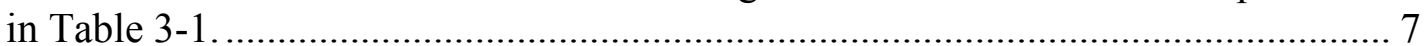

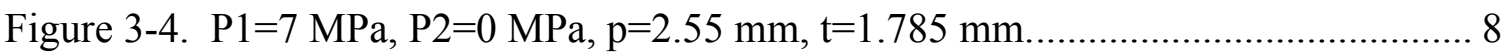

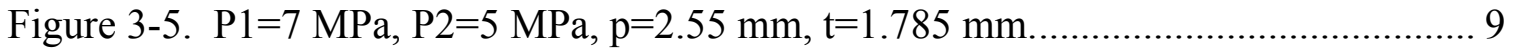

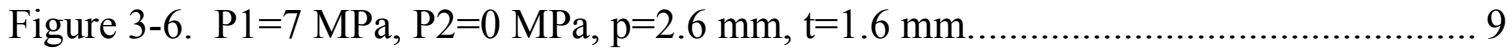

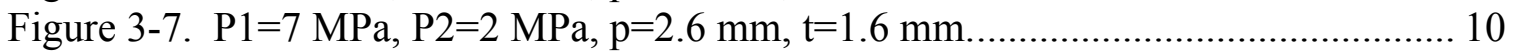

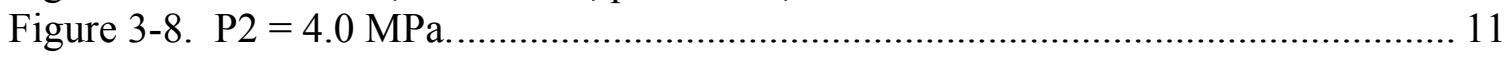

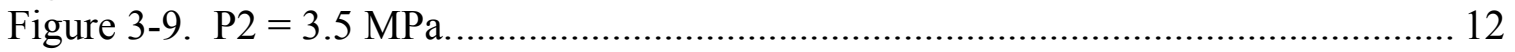

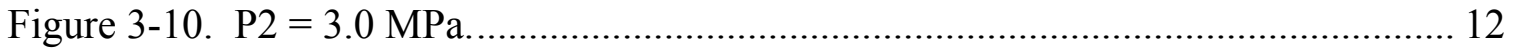

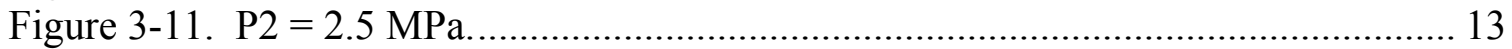

Figure 3-12. Acceptable array for $\mathrm{P} 1=7 \mathrm{MPa}, \mathrm{P} 2=3.5 \mathrm{MPa}, \mathrm{p}=2.25 \mathrm{~mm}, \mathrm{t}=1.17 \mathrm{~mm}$, $\mathrm{P} \infty=7 \mathrm{MPa}$

Figure 3-13. Acceptable array for $\mathrm{P} 1=7 \mathrm{MPa}, \mathrm{P} 2=5 \mathrm{MPa}, \mathrm{p}=1.8 \mathrm{~mm}, \mathrm{t}=1.0 \mathrm{~mm}, \mathrm{P}_{\infty}$

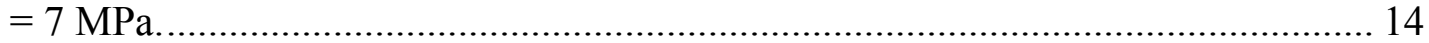

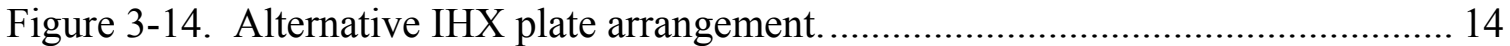

Figure 3-15. Annular pipe design for the IHTL - a) fluid flows and b) cross section identifying the relevant radii. Temperatures, $T_{i}$, are associated with each radius $r_{i} .15$

Figure 3-16. The effect of separation distance on cold leg diameter in an annular configuration.

Figure 3-17. Mean fluid temperature as a function of distance along the separate hot and cold legs for a liquid salt (FLiNaK) and low pressure helium (2 MPa). The IHX and PHX are located at $\mathrm{x}=0$ and $500 \mathrm{~m}$, respectively

Figure 3-18. The temperature profile of the hot and cold legs for the annular design with $500 \mathrm{~m}$ separation distance and insulation on the exterior of the inner pipe. The IHX and $\mathrm{PHX}$ are located at $\mathrm{X}=0$ and $500 \mathrm{~m}$, respectively.

Figure 3-19. The temperature profile of the hot and cold legs for the annular design with a $500 \mathrm{~m}$ separation distance and insulation on the interior of the inner pipe. The IHX and PHX are located at X $=0$ and $500 \mathrm{~m}$, respectively. 


\section{INTRODUCTION}

Currently the Department of Energy is actively pursuing the development of high temperature reactors to provide heat for various processes, some of which yield hydrogen as an energy carrier. Due to safety concerns the hydrogen production facility cannot be integrated into the nuclear power production facility. The heat generated by a high temperature nuclear reactor must be transported over significant distances to the hydrogen production facility. It is the job of the intermediate heat transport loop (IHTL) to efficiently transfer heat from the nuclear power plant to the hydrogen production facilities. As a minimum, the IHTL consists of an intermediate heat exchanger (IHX), piping to carry the heat transfer fluid, a process heat exchanger (PHX) to transfer the energy to the hydrogen facility and a pumping system. The final design of the IHTL may also include various valves to isolate the IHTL from the primary cooling circuit of the nuclear power plant as well as from the hydrogen production facility. Auxiliary heat systems and fluid storage tanks will also be required but design work has not progressed sufficiently to yield the most appropriate configuration.

Currently the Next Generation Nuclear Plant (NGNP) is expected to supply heat to the heat transfer loop at temperatures between $900-1000^{\circ} \mathrm{C}$. The hydrogen production facility requires a minimum temperature of $800^{\circ} \mathrm{C}$ for the thermochemical production of hydrogen, i.e. the Sulfur-Iodine cycle, and about $700^{\circ} \mathrm{C}$ for high temperature electrolysis (HTE) [Independent Technology Review Group, 2004]. Therefore the components of the heat transport system will be subjected to temperatures where materials issues, such as high temperature strength and creep, will be a concern. Also, current recommendations [Smith. et. al., 2005] site the hydrogen production facility approximately 90 meters away from the NGNP with distances of up to 500 meters away being considered. Significant heat loss during heat transport over these distances has been a concern. Therefore, this IHTL system will have to receive heat efficiently from the NGNP, transport it over large distances without excessive heat loss and, finally, efficiently transfer it to the hydrogen production facility at temperatures of at least $700^{\circ} \mathrm{C}$ for high temperature electrolysis and $800^{\circ} \mathrm{C}$ for thermochemical cycles.

Other engineering concerns involve the integrity of the materials of construction in the expected operating environment of the IHTL. Two fluids are currently under consideration for use as the high temperature heat transfer medium, namely helium or liquid (molten) salt. A swiftly moving (on the order of $6 \mathrm{~m} / \mathrm{s}$ ) liquid salt raises concerns related to high temperature corrosion of loop components as well as erosion due to the entrainment of corrosion products. The use of helium as a heat transfer medium presents less of a corrosion problem but erosion (or, rather the particles and impurities entrained within the helium fluid) may be more of a factor since velocities approaching $200 \mathrm{~m} / \mathrm{s}$ may be realized [Davis, et. al., 2005]. Also the heat transfer system will be supplying heat to decompose concentrated sulfuric acid vapors into $\mathrm{SO}_{2}, \mathrm{SO}_{3}$ and water and, therefore, the process heat exchanger will be exposed to highly corrosive conditions. Finally, the operating temperature of the IHTL components is very high $\left(800-900^{\circ} \mathrm{C}\right)$ and, when combined with significant pressure differentials across the IHX, PHX and pipe walls, the potential for creep deformation is an issue. 
This report begins to explore the engineering issues involved with the major components of the IHTL, namely the IHX, PHX and the fluid transport piping. Specifically this report evaluates the stresses within a printed circuit heat exchanger (PCHE) due to the pressure differential between the primary nuclear power plant coolant and the IHTL heat transfer fluid. The report also evaluates the heat loss for two piping configurations, namely separate "hot" and "cold" fluid transport legs and an annular pipe design with the "hot" fluid flowing through the center and the "cold" fluid flowing in the opposite direction through the annular space. Both helium (at $2 \mathrm{MPa}$ and $7 \mathrm{MPa}$ ) and liquid salt (Flinak) are analyzed and compared. Materials issues are also discussed for the different configurations and fluids. Finally, this report addresses the use of a compact heat exchanger for the PHX for the Sulfur-Iodine thermochemical hydrogen production process. The compact heat exchanger is compared to a standard pack bed heat exchanger/chemical reactor of the tube in shell design. 


\section{KEY REQUIREMENTS AND ASSUMPTIONS}

As mentioned previously the designs of the high temperature nuclear power plant, IHTL and the hydrogen production facility are not mature and various assumptions and requirements were used in the preparation of this report. The IHTL is assumed to be of the simplest design, resembling Configuration 1 in the report by Davis, et. al., 2005, Figure 2-1. The IHTL is assumed to consist of the IHX, PHX and the piping connecting the two components. Pumps to pressurize and circulate the fluid are neglected as is the energy they contribute to the system. These details are left for more detailed analyses in the future.

The most important assumption is the temperature of the primary coolant supplied to the IHX. Various reports have recommended temperatures lower than the $1000^{\circ} \mathrm{C}$ originally envisioned [Independent Technology Review Group, 2004]. This issue was not addressed directly in this report. However, it was assumed the heat transfer fluid (either helium or liquid salt) of the IHTL exiting the IHX would be on the order of $850^{\circ} \mathrm{C}$.

Furthermore, the PHX was assumed to be capable of transferring $50 \mathrm{MW}$ thermal energy to the hydrogen production process and is manifested as a drop in the temperature of the IHTL fluid. Other assumptions and requirements, specific to the individual analyses, will be noted in the relevant sections of this report.

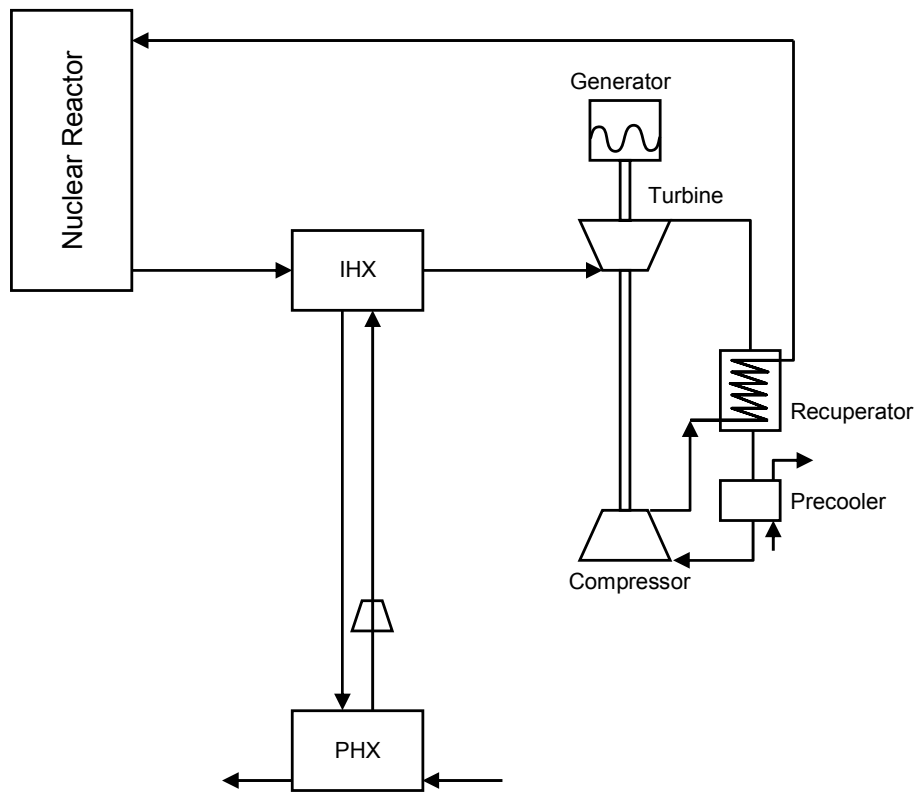

Figure 2-1. Direct electrical cycle and serial IHX (Configuration 1) 


\section{RESULTS}

The results of the stress analysis of the compact IHX are presented in Section 3.1. The thermal evaluation of two different piping configurations for the IHTL are presented in Section 3.2 and finally a simplified analysis and comparison of two PHX designs are given in Section 3.3.

\subsection{Intermediate Heat Exchanger Stress Analysis}

Current concepts for the NGNP utilize a Printed Circuit Heat Exchanger (PCHE) for the intermediate heat exchanger (IHX) to interface with the IHTL. This type of heat exchanger, manufactured by Heatric, uses a lamination of plates, which have chemically etched semi-circular channels between each diffusion-bonded layer, as shown in Figures 3-1 and 3-2. This type of heat exchanger is compact, efficient, and capable of highpressures, all of which are attractive to the NGNP program. However, a stress analysis is necessary to verify that the PCHE is operating in an acceptable range because of the high operating temperature.

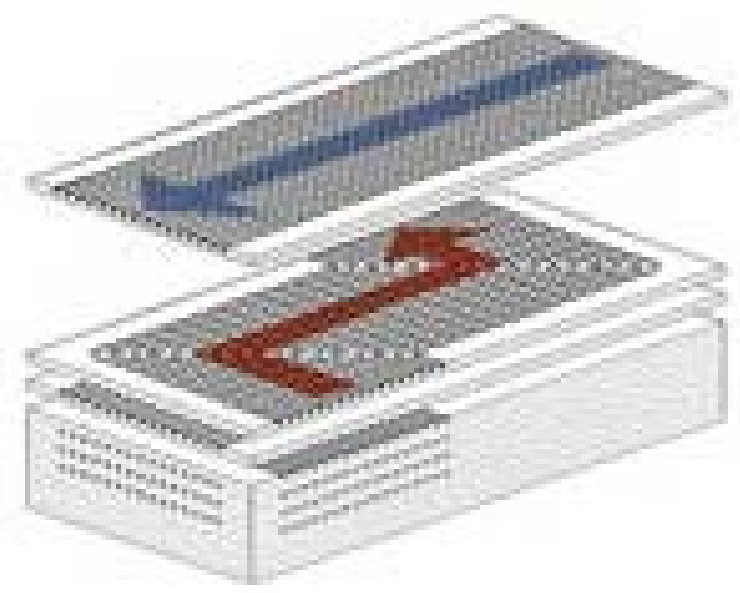

Figure 3-1. Diffusion bonded layers in a Heatric heat exchanger 


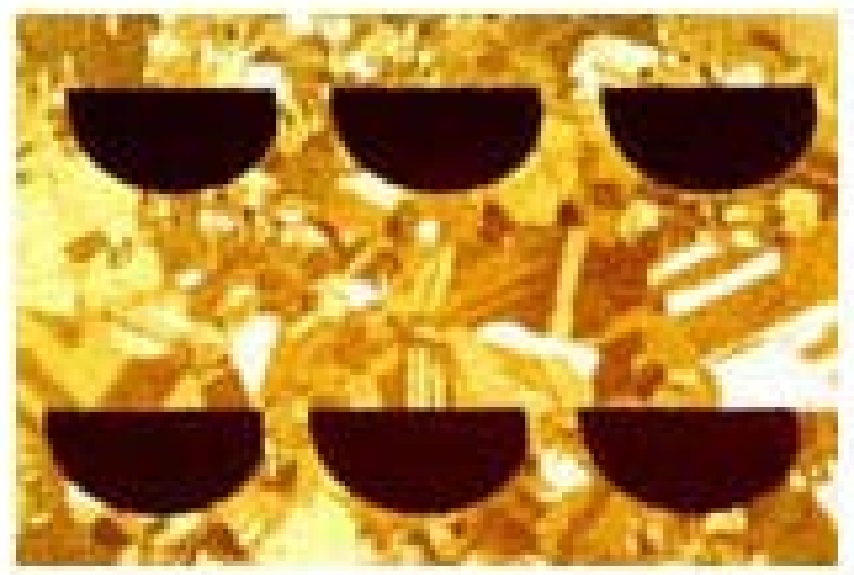

Figure 3-2. Flow channel cross section in Heatric diffusion-bonded heat exchanger.

A simplified stress analysis on this type of heat exchanger has been performed previously [Davis, et. al., 2005] which yielded fluid channel configurations based on the pressure differential between the primary coolant of the nuclear reactor and the fluid of the IHTL. This more detailed stress analysis was performed to verify the stresses within the PCHE fall below the expected allowable value, and to assure that this type of construction is suitable for the $900^{\circ} \mathrm{C}$ operating conditions desired for the NGNP. The conditions investigated are shown in Table 3-1. The definitions of the pitch-to-diameter ratios of $\mathrm{p} / \mathrm{d}$ and $\mathrm{t}_{\mathrm{p}} / \mathrm{d}$ are given in Figure $3-3$. The primary coolant from the nuclear reactor is assumed to be maintained at $7 \mathrm{MPa}, \mathrm{P}_{\mathrm{i}}$, while the pressure of the fluid in the IHTL channels was allowed to vary from 0 to $7 \mathrm{MPa}, \mathrm{P}_{\mathrm{o}}$. The $2 \mathrm{MPa}$ scenario includes either low pressure helium or liquid salt.

Table 3-1. Summary of the stress calculations for the IHX

\begin{tabular}{|c|c|c|l|}
\hline $\mathrm{P}_{\mathrm{i}} / \mathrm{P}_{\mathrm{o}}(\mathrm{MPa})$ & $\mathrm{p} / \mathrm{d}$ & $\mathrm{t}_{\mathrm{p}} / \mathrm{d}$ & \multicolumn{1}{|c|}{ Comments } \\
\hline $7 / 0$ & 1.70 & 1.19 & Maximum differential pressure \\
\hline $7 / 5$ & 1.20 & 0.57 & High-pressure helium \\
\hline $7 / 2$ & 1.50 & 0.78 & $\begin{array}{l}\text { Low-pressure helium or liquid } \\
\text { salt }\end{array}$ \\
\hline
\end{tabular}




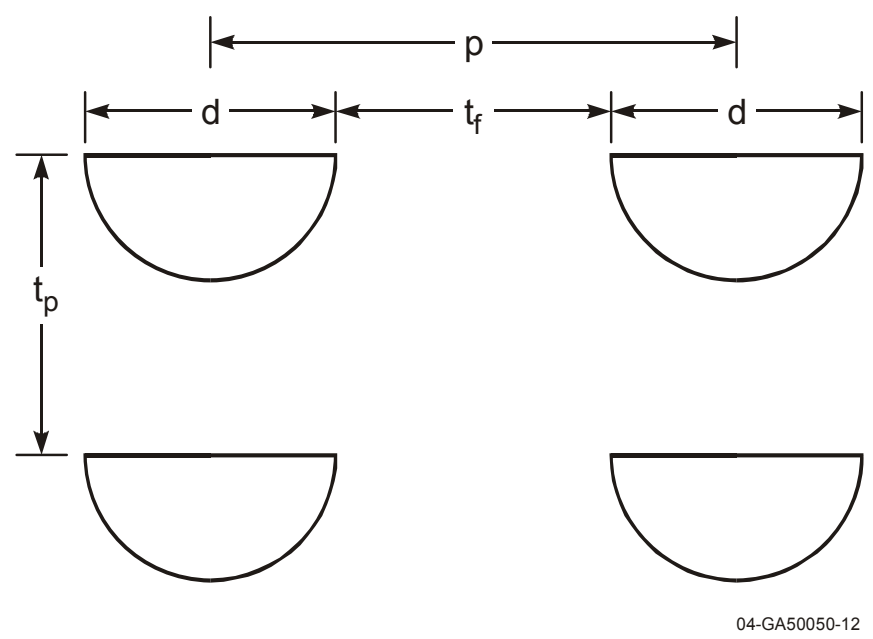

Figure 3-3. Illustration of the $\mathrm{IHX}$ channel configuration and definition of the parameters in Table 3-1.

Finite Element Analysis (FEA) models were developed using the I-DEAS $11 \mathrm{NX}$ computer code and various arrays of flow channel pitches and plate thicknesses, which are noted as ' $p$ ' and ' $t$ ' in the stress plots. The allowable stress was assumed to be $10 \mathrm{MPa}$, which is consistent with a 100,000-hour life for Alloy 617 at $900^{\circ} \mathrm{C}$ at a factor of safety of 2. It should be noted that this material is in a creep-rupture failure regime at this temperature, and as such has a finite life. For comparison purposes the yield strength of Alloy 617 is about $175 \mathrm{MPa}$ for short duration loads. The plots of the von Mises stress are shown in Figures 3-4, through 3-7. The pressures for the hot and cold channel are noted as P1 and P2, respectively, with each of the channels having a diameter of $1.5 \mathrm{~mm}$. In all of these cases, the exterior of the PCHE is at atmospheric pressure. In each plot the elements were removed (colored black) where the stresses exceeded the design stress, 10 $\mathrm{MPa}$, which gives one a picture of general areas where failure is eventually expected. In Figure 3-4, which is based on the ratios given in Table 1 and $\mathrm{P} 2=0 \mathrm{MPa}$, it is obvious that significant areas are above the allowable stress. Moreover, the corner regions of the channel are in tension, which will initiate a crack and ultimately lead to de-lamination of the heat exchanger. Even larger areas above the allowable stress were obtained using the ratios from Table 3-1 when $\mathrm{P} 2$ was increased to $2 \mathrm{MPa}$ and $5 \mathrm{MPa}$. Consequently, additional calculations were made in which similar levels of stress were obtained at the different values of $\mathrm{P} 2$ by adjusting the values of $\mathrm{p}$ and $\mathrm{t}$. These results, which generally used larger ratios than those given in Table 3-1, are shown in Figures 3-5 through 3-7.

Since the corners of these flow channels are an obvious stress riser, the solution would seem to be to pursue a design that would have circular rather than semi-circular crosssections. However, even if the cross section were round, the von Mises stress would still exceed the $10 \mathrm{MPa}$ allowable stress. For example, if the channel were a thick walled cylinder, the internal channel surface would still have a minimum von Mises stress $\sim 12$ $\mathrm{MPa}$ even at an infinite wall thickness. At a more realistic wall thickness, where the channel diameter and the wall thickness are equal, a von Mises stress of 13.7 MPa is expected. The conclusion is that the previously analyzed configuration for the PCHE is 
not suitable for Alloy 617 for an operating lifetime of 100,000 hours at $900^{\circ} \mathrm{C}$, although other materials, such as silicon carbide, may enable the use of this configuration.

To alleviate the high stresses in the corners, it has been suggested that the entire IHX be contained (immersed) in a vessel that operates at $7 \mathrm{MPa}$. The containment wall of this vessel could operate at less than $900^{\circ} \mathrm{C}$, which would result in much higher allowable stresses in the outer vessel material.

Ultimately this can lead to a zero von Mises stress if the hot and cold channels are both operated at $7 \mathrm{MPa}$. This is not to say that the maximum principal stresses in the material would be zero, but rather that the von Mises stress (which is used in the distortion-energy failure prediction methodology) would not predict failure. Indeed, experience has shown that the distortion-energy failure theory is the best failure prediction methodology and is the basis for many design codes. Therefore, if the hot and cold channels, as well as the immersion pressure were equal, the channel pitch and the plate thickness could be as small as desired. However, current concepts have the secondary side of the IHX operating at pressures less than $7 \mathrm{MPa}$. This differential pressure will ultimately lead to stresses in the PCHE.

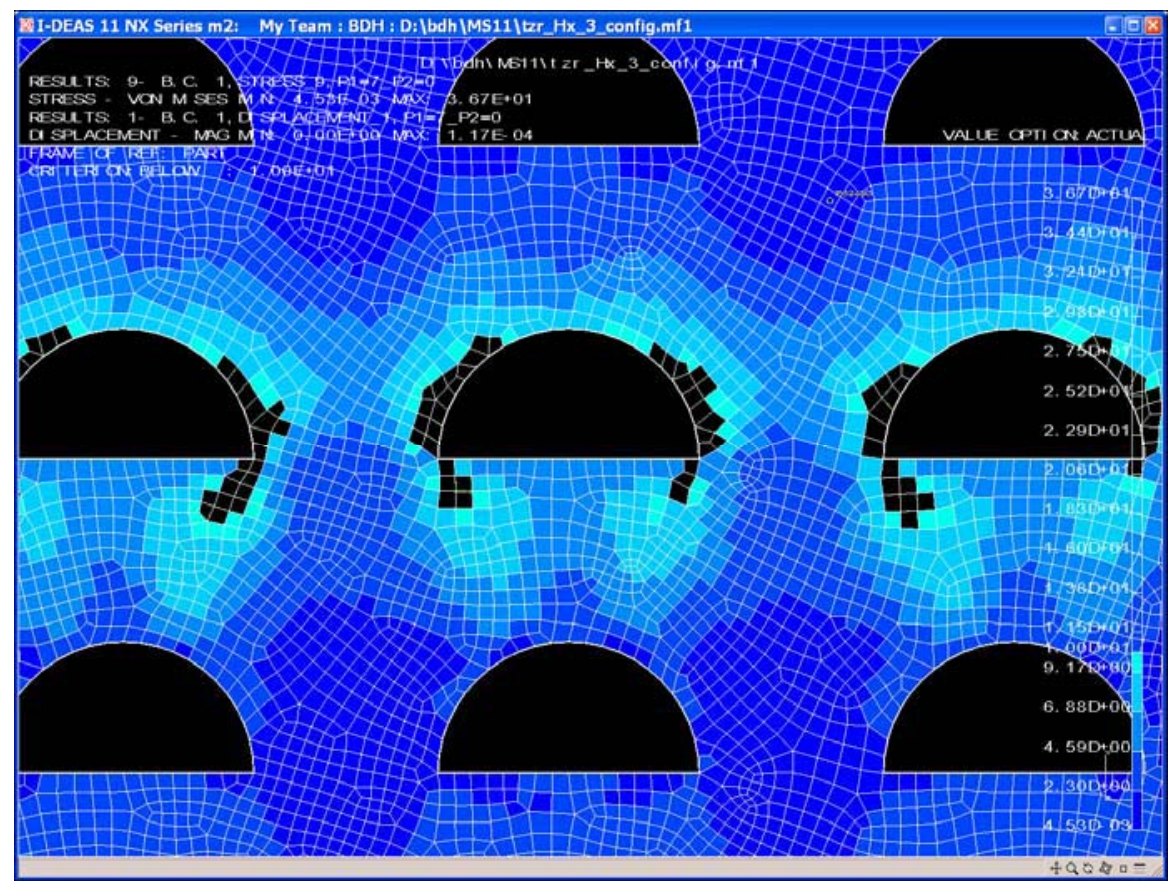

Figure 3-4. $P 1=7 \mathrm{MPa}, \mathrm{P} 2=0 \mathrm{MPa}, \mathrm{p}=2.55 \mathrm{~mm}, \mathrm{t}=1.785 \mathrm{~mm}$. 


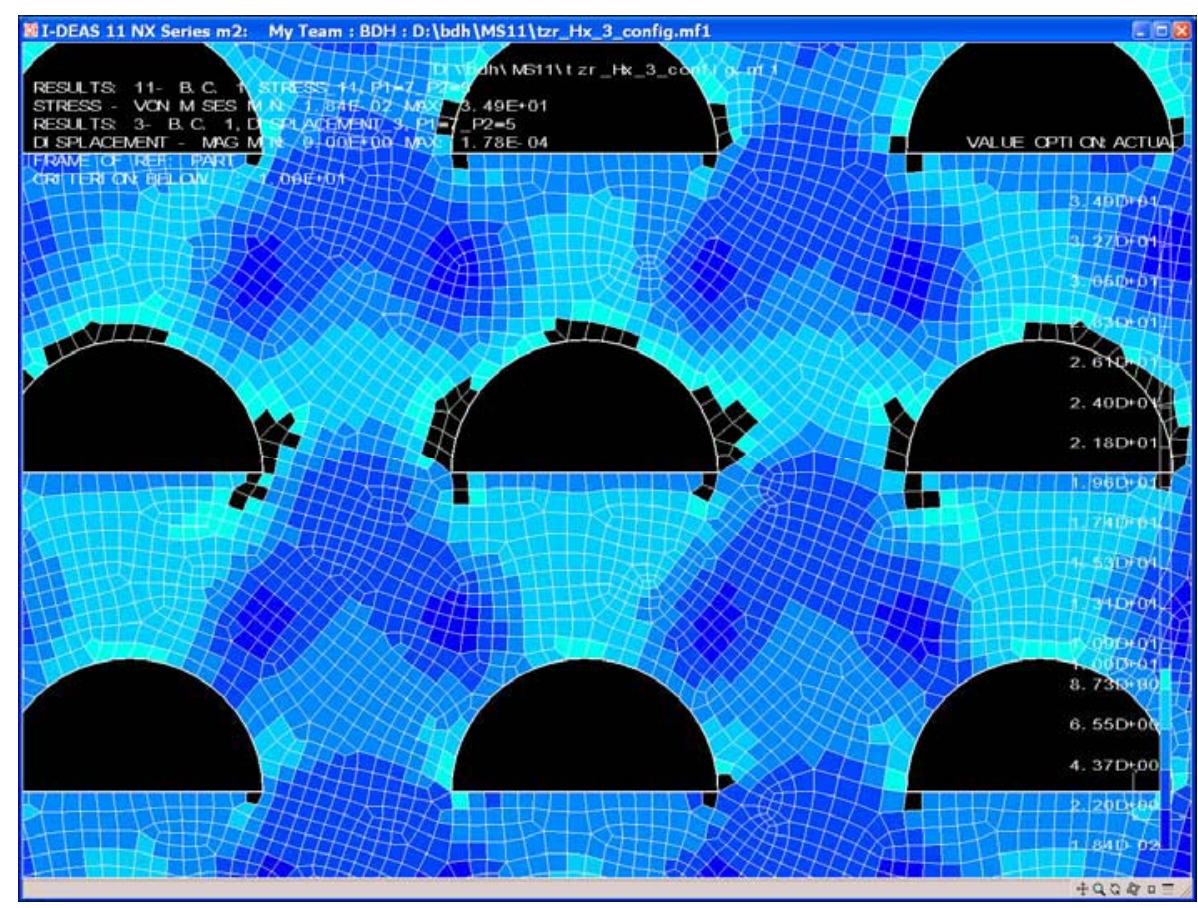

Figure 3-5. $P 1=7 \mathrm{MPa}, \mathrm{P} 2=5 \mathrm{MPa}, \mathrm{p}=2.55 \mathrm{~mm}, \mathrm{t}=1.785 \mathrm{~mm}$.

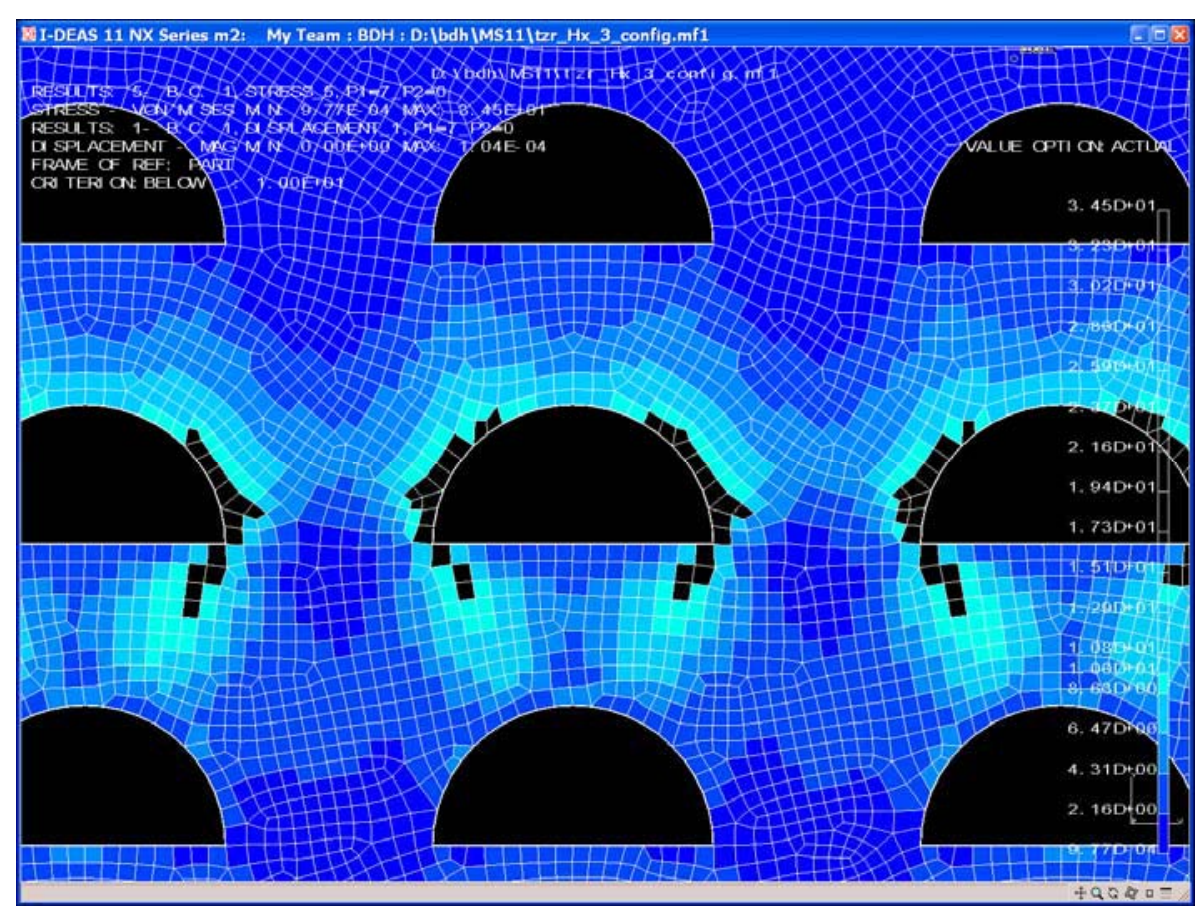

Figure 3-6. $\mathrm{P} 1=7 \mathrm{MPa}, \mathrm{P} 2=0 \mathrm{MPa}, \mathrm{p}=2.6 \mathrm{~mm}, \mathrm{t}=1.6 \mathrm{~mm}$. 


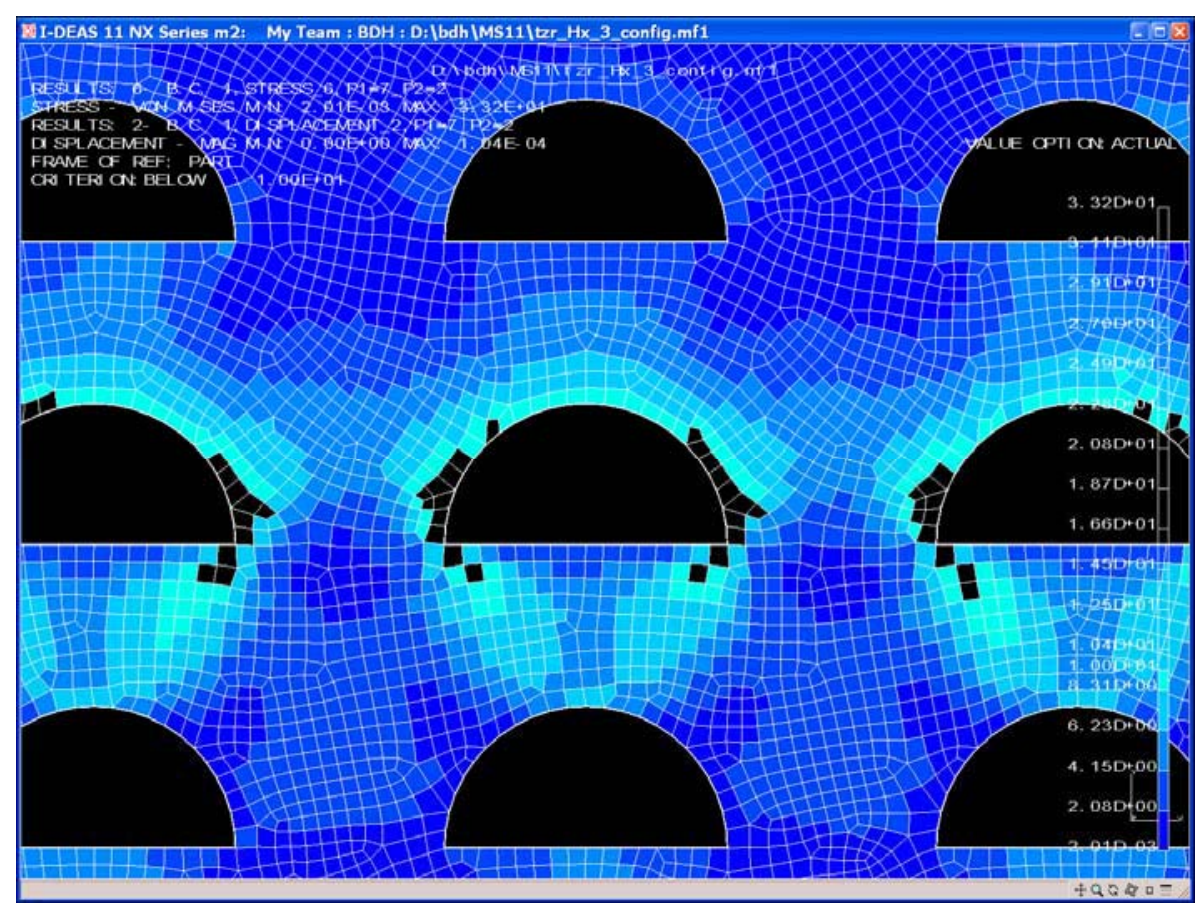

Figure 3-7. $P 1=7 \mathrm{MPa}, \mathrm{P} 2=2 \mathrm{MPa}, \mathrm{p}=2.6 \mathrm{~mm}, \mathrm{t}=1.6 \mathrm{~mm}$.

Since no von Mises stresses are expected in the primary (hot) flow channels (which operate at $7 \mathrm{MPa}$ ) the geometry of the secondary (cold) channels was analyzed to determine at what secondary pressure the von Mises stresses exceeded $10 \mathrm{MPa}$. For simplicity, only a single channel was analyzed with significant enough wall thickness to minimize edge effects. The secondary pressure was varied from 0 to $7 \mathrm{MPa}$ in $0.5 \mathrm{MPa}$ steps, while the immersion pressure was held constant at $7 \mathrm{MPa}$. The results indicate that when the secondary pressure drops below $3.0 \mathrm{MPa}$, significant corner stresses begin to occur. The stress plots that illustrate this transition are shown in Figures 3-8 through 311. It may be argued that these stresses are compressive and therefore will not lead to crack formation. However, ASME design codes would not permit von Mises stresses which exceeds the allowable (10 MPa) stress. A more sophisticated creep analysis and an ASME code case could be pursued to possibly allow this compressive stress. For the purposes of this initial analysis, the lower level for the secondary pressure is judged to be about $3 \mathrm{MPa}$. It should be noted that at $3 \mathrm{MPa}$ internal pressure there are still corner elements that are above $10 \mathrm{MPa}$. This is ignored due to the limitations of FEA on corner geometries. Obviously, as the pressure drops to $2.5 \mathrm{MPa}$ more elements are shown to be above $10 \mathrm{MPa}$ (colored black).

As seen above, the minimum pressure of the secondary side is judged to be $3.0 \mathrm{MPa}$; therefore no full channel arrays were analyzed at secondary pressures below this value. To find acceptable array geometry, as defined by values of " $t$ " and " $p$ ", for 3.5 MPa and $5.0 \mathrm{MPa}$ secondary pressures, multiple channel array geometries were analyzed. Although not optimized, acceptable (or nearly so) arrays for 3.5 and $5.0 \mathrm{MPa}$ are shown in Figures 3-12 and 3-13. 
To reduce the immersion pressure requirement, and therefore reduce the size and cost of the immersion vessel, an alternate arrangement is suggested as shown in Figure 3-14. In this case the stacked plates have matching holes drilled into them that serve as channels for the high-pressure primary side of the heat exchanger. The low-pressure side would have semi-circular channels similar to the Heatric arrangement. Since the primary side channels are round (and have no stress risers) they can better withstand the applied stresses, thus reducing the need for immersion pressure. Since the immersion pressure is reduced, the secondary pressure could likewise be reduced if desired. Unfortunately, this construction technique leads to a cross flow type heat exchanger rather than the desired counter flow arrangement. However by using a serpentine path along a long heat exchanger (like a baffle in a tubes-in-shell type heat exchanger), counterflow efficiencies may be approached.

As a result of this stress analysis check, the following conclusions are reached:

1) Conventional arrangement of the PCHE (no external pressure) leads to stresses in Alloy 617 (the preferred alloy) that exceed the expected allowable stress for 100,000 hours of operation at $900^{\circ} \mathrm{C}$.

2) The immersion technique is a viable way to keep PCHE stresses within acceptable limits.

3) There is a lower limit on the secondary side pressure. With a $7 \mathrm{MPa}$ immersion pressure, the secondary should be 3.0 MPa or greater.

4) An alternate heat exchanger construction technique can lead to lower immersion pressures and higher primary-secondary differential pressure.

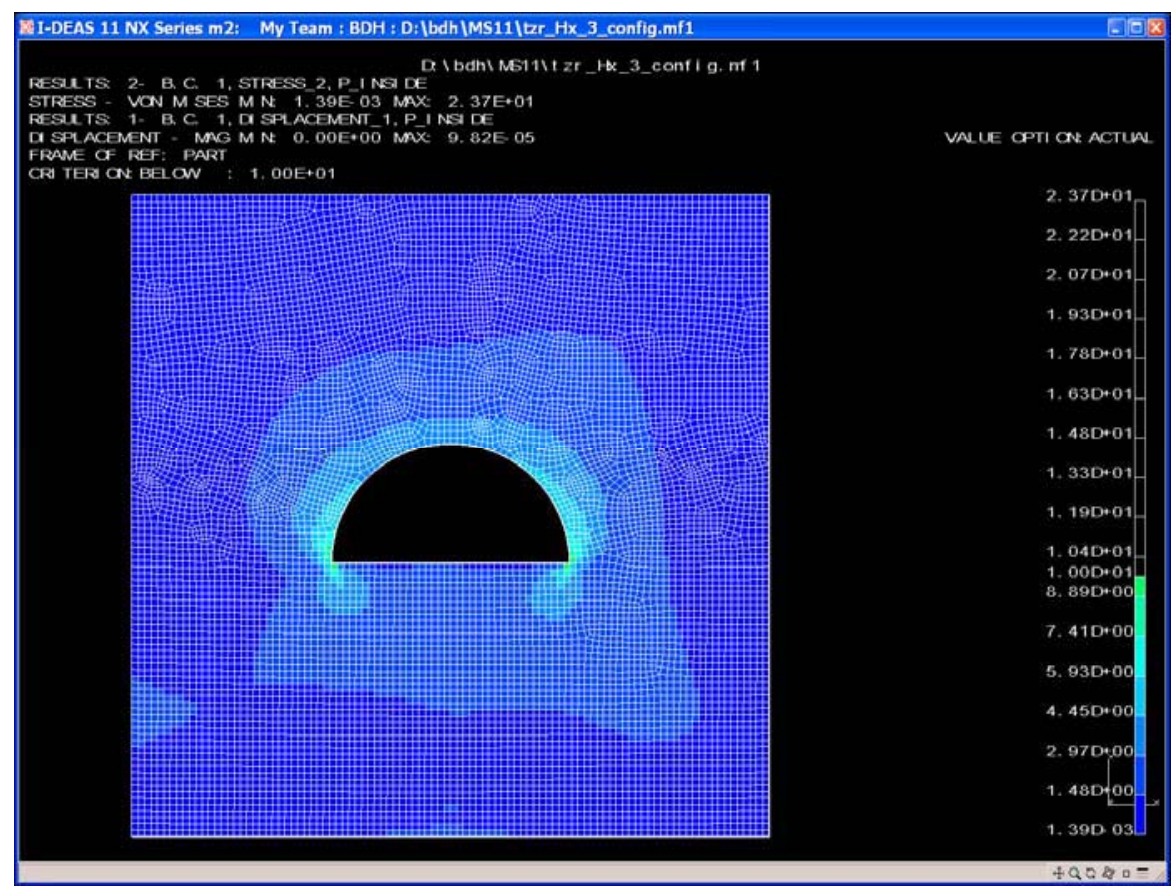

Figure 3-8. $\mathrm{P} 2=4.0 \mathrm{MPa}$. 


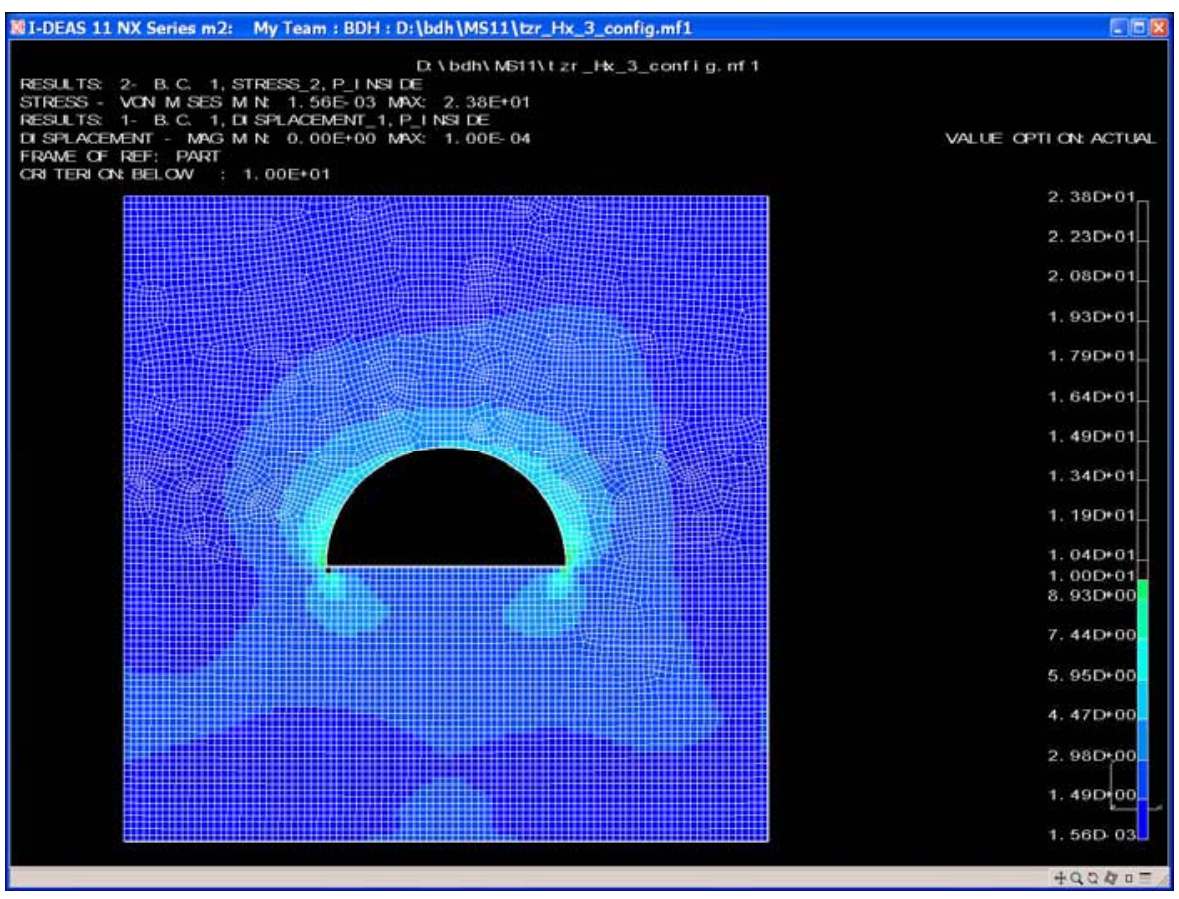

Figure 3-9. $\mathrm{P} 2$ = $3.5 \mathrm{MPa}$.

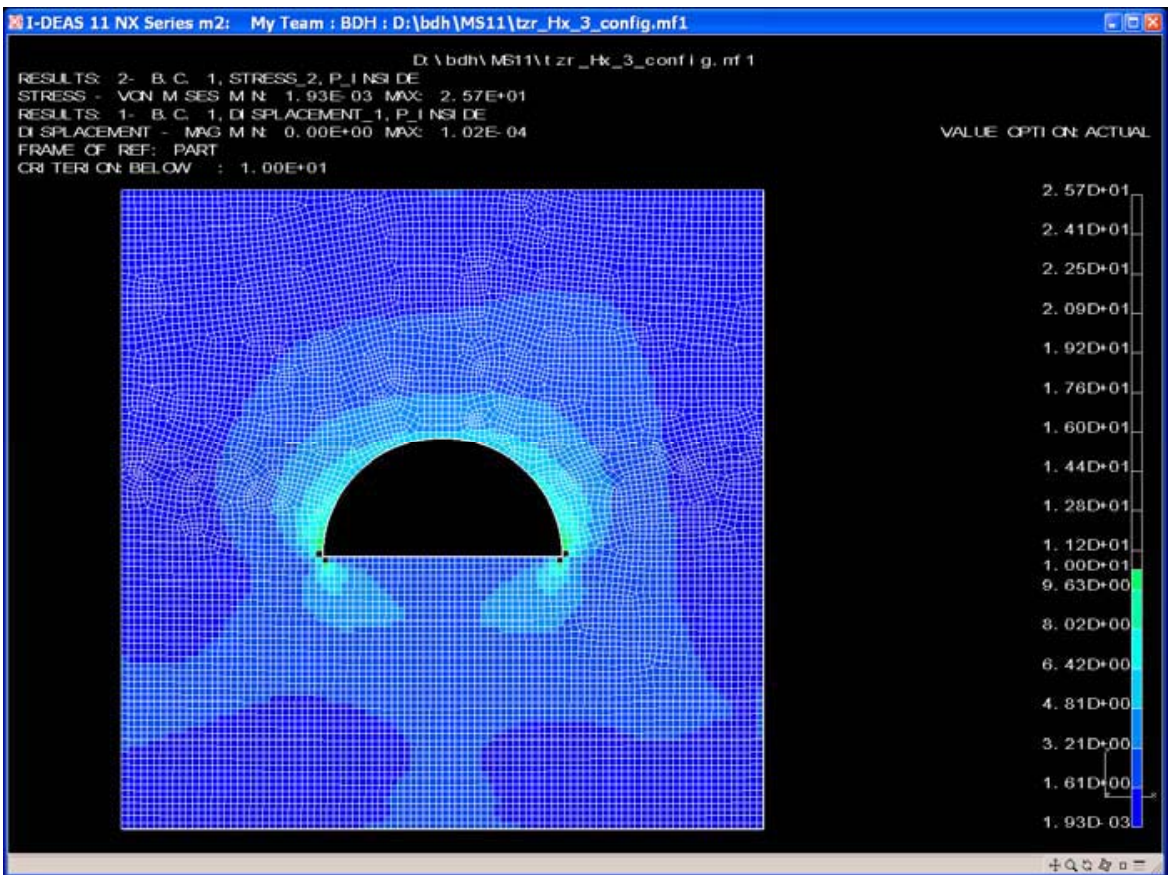

Figure 3-10. P2 = 3.0 MPa. 


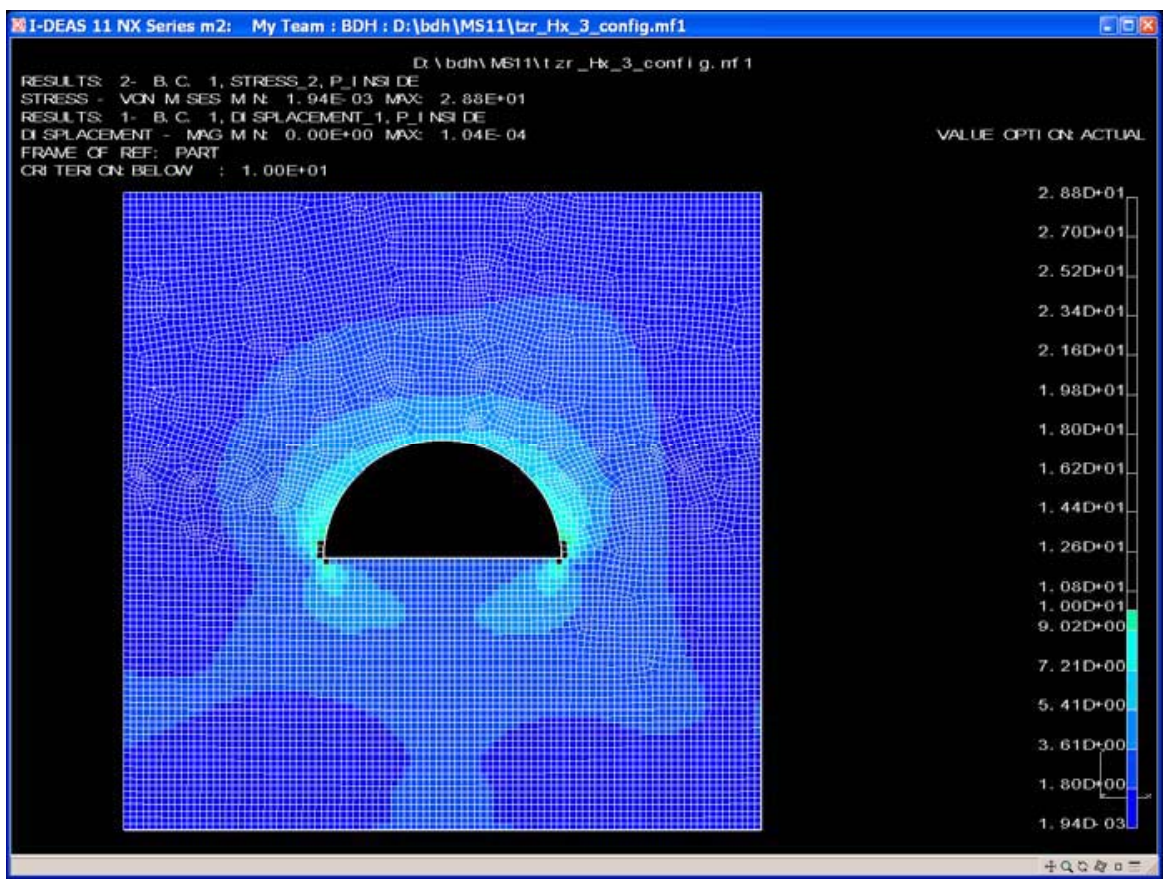

Figure 3-11. P2 = 2.5 MPa.

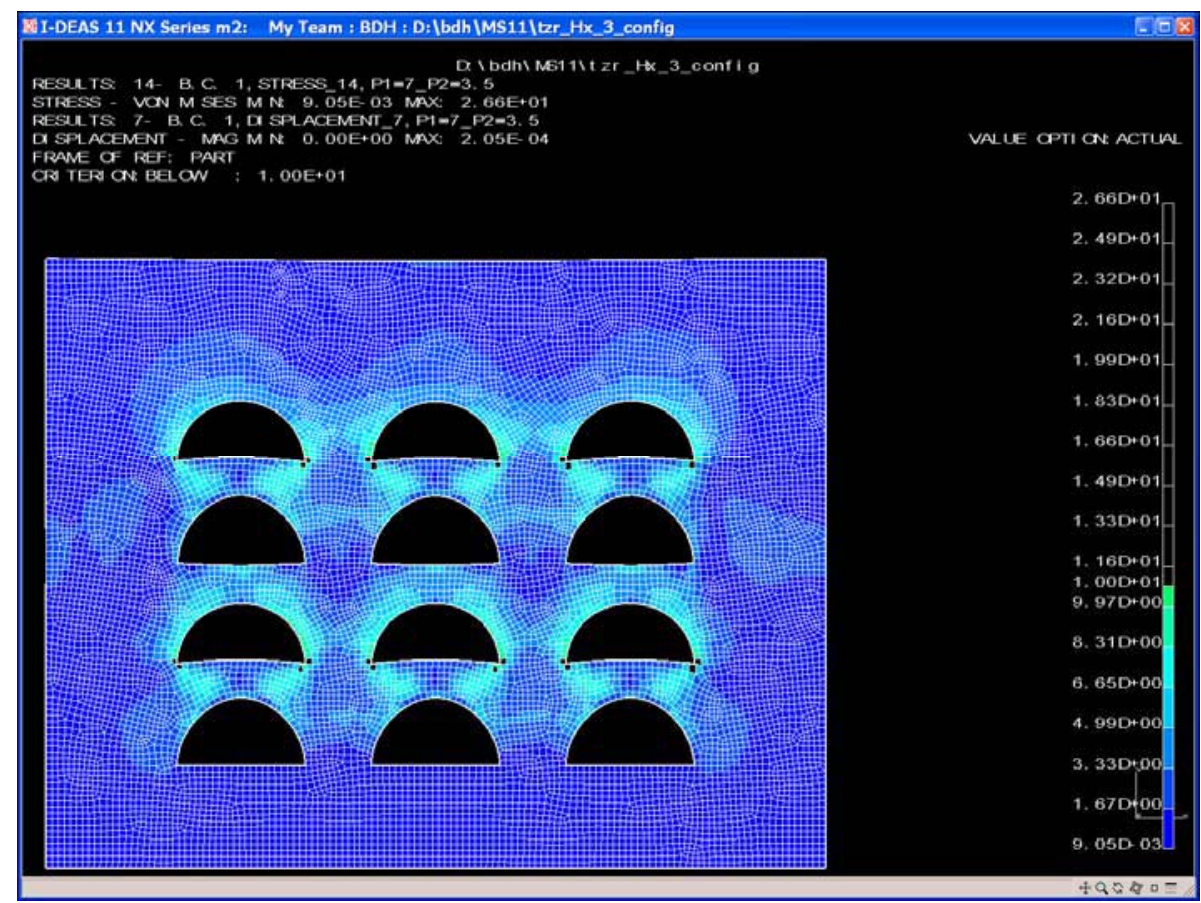

Figure 3-12. Acceptable array for $\mathrm{P} 1=7 \mathrm{MPa}, \mathrm{P} 2=3.5 \mathrm{MPa}, \mathrm{p}=2.25 \mathrm{~mm}, \mathrm{t}=1.17$ $\mathrm{mm}, \mathrm{P} \infty=7 \mathrm{MPa}$. 


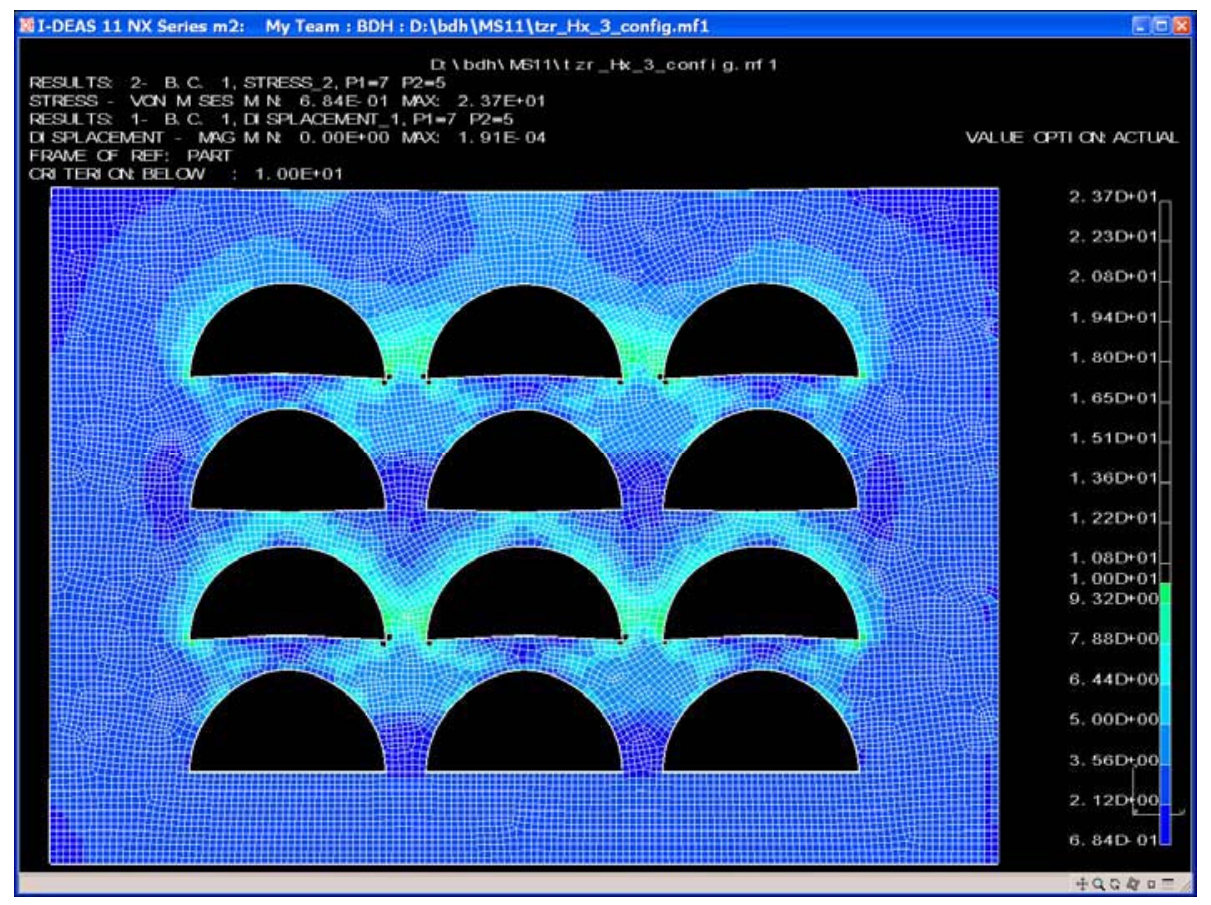

Figure 3-13. Acceptable array for $\mathrm{P} 1=7 \mathrm{MPa}, \mathrm{P} 2=5 \mathrm{MPa}, \mathrm{p}=1.8 \mathrm{~mm}, \mathrm{t}=1.0 \mathrm{~mm}, \mathrm{P}_{\infty}$ $=7 \mathrm{MPa}$.

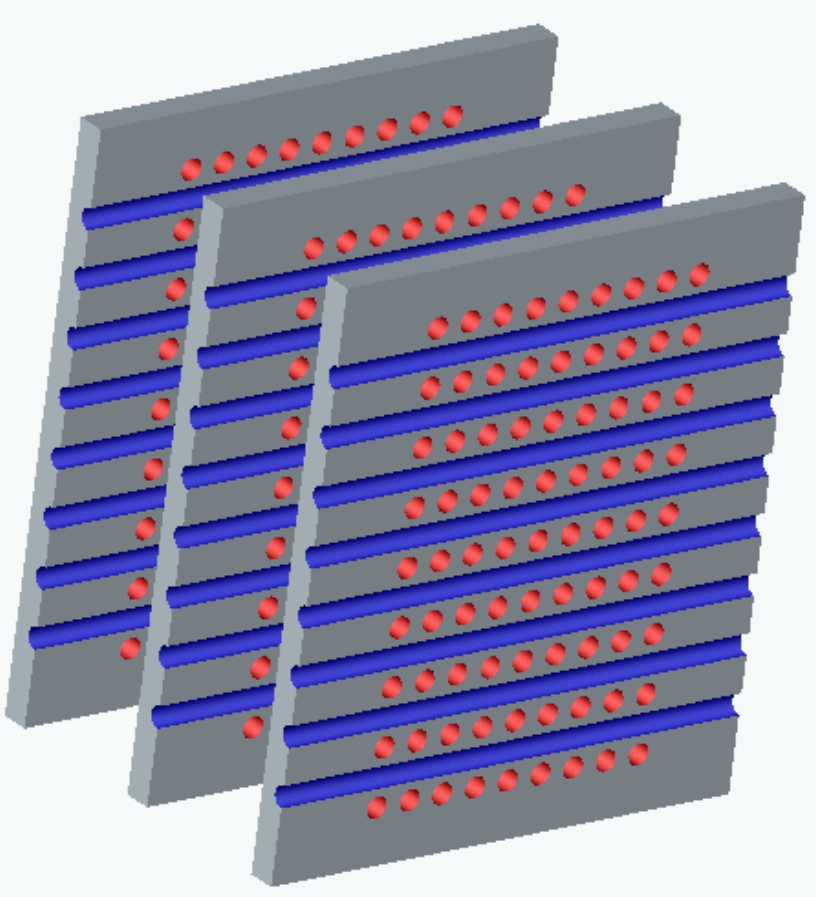

Figure 3-14. Alternative IHX plate arrangement. 


\subsection{Thermal Analysis of the IHTL Pipe Configuration}

In order for the viable operation of the various hydrogen production processes, the IHTL must deliver heat at high temperatures $\left(>700^{\circ} \mathrm{C}\right)$. Concerns have been raised as to whether this can be done economically, considering the potentially large distances over which the heat may have to be transported. Excessive heat loss during transport has the potential of lowering the fluid temperature to a point below that required by the hydrogen production process. Conversely, excessive insulation to maintain the required fluid temperature may be cost prohibitive. This analysis was undertaken to explore the temperature and heat losses under the expected operating conditions and over the range of transport distances being considered.

Two piping configurations were evaluated. The first is simply separate hot and cold insulated pipes and is considered the baseline configuration. The second configuration is an annular design, Fig. 3-15, in which the "hot" fluid travels through the central pipe and the "cold" fluid travels in the opposite direction in the annular space. Also, both helium and liquid salt, FLiNaK, are considered. The transport distance was varied from 90 to 500 meters to explore the extremes in thermal behavior.

a)

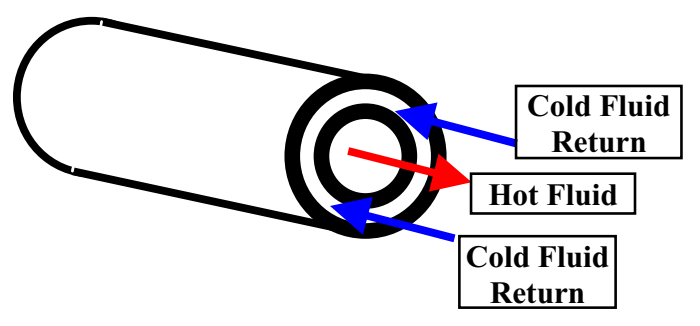

b)

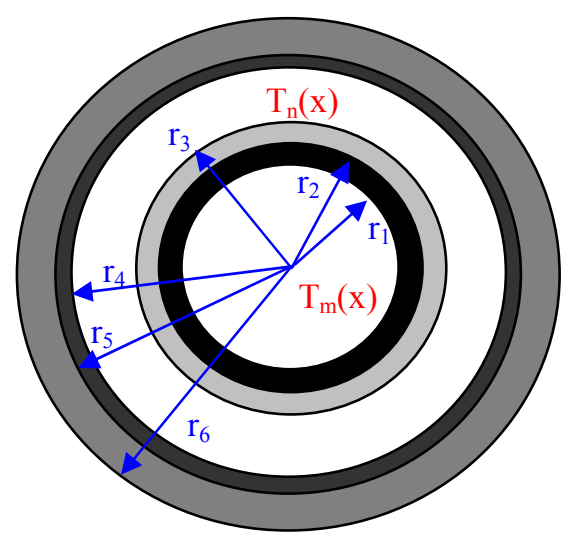

Figure 3-15. Annular pipe design for the IHTL $-a$ ) fluid flows and $b$ ) cross section identifying the relevant radii. Temperatures, $T_{i}$, are associated with each radius $r_{i}$.

\subsubsection{Key Assumptions and Requirements}

Many of the pipe parameters have been based on the analysis by Davis, et. al., 2005. Specifically the pipe diameters for the hot and cold legs of the baseline configuration were taken from that report and were based on a 0.05 MPa pressure drop within the leg over the transportation distance. The pipe wall thickness, based on the operating temperature of each leg and the material strength at that temperature, was also determined in the above report. The results are summarized in Table 2. The maximum pipe stress 
was limited to $10 \mathrm{MPa}$, approximately half the rupture strength of I-617 at $900^{\circ} \mathrm{C}$ for a rupture life of $10^{5}$ hours.

Table 3-2. Summary of the stress calculations for the IHTL piping

\begin{tabular}{|l|c|c|c|l|}
\hline Leg & $\begin{array}{c}\mathrm{P}_{\mathrm{i}}(\mathrm{MPa}) / \\
\mathrm{T}\left({ }^{\circ} \mathrm{C}\right)\end{array}$ & $\sigma_{\mathrm{D}}(\mathrm{MPa})$ & $\mathrm{t} / \mathrm{d}$ & \multicolumn{1}{|c|}{ Comments } \\
\hline Hot & $2 / 900$ & 10 & 0.11 & Low-pressure helium or liquid salt \\
\hline Hot & $3.5 / 900$ & 10 & 0.22 & Intermediate pressure \\
\hline Hot & $5 / 900$ & 10 & 0.37 & Intermediate pressure \\
\hline Hot & $7 / 900$ & 10 & 0.69 & High-pressure helium \\
\hline Cold & $2 / 500$ & 120 & 0.01 & Low-pressure helium \\
\hline Cold & $2 / 700$ & 42 & 0.05 & Low-pressure liquid salt \\
\hline Cold & $7 / 500$ & 120 & 0.03 & High-pressure helium \\
\hline
\end{tabular}

For the annular configuration the inner, $r_{1}$, and outer pipe, $r_{4}$, radii needed to be determined. (The pipe radii for the separate hot and cold leg configuration were calculated previously in the report by Davis, et. al., 2005.) Therefore, an evaluation was performed to determine the effects of separation distance on an annular configuration of the heat transport loop piping in which the hot leg was assumed to be located inside the cold leg. Three different working fluids were evaluated, including low-pressure helium, high-pressure helium, and molten salt. The inner diameter of the hot leg, $\mathrm{r}_{1}$, was based on the analysis reported by Davis et al., 2005 for Configuration 1. The thickness-to-inner diameter ratios of the hot leg were set to 0.14 for Flinak, the liquid salt, and 0.12 for helium. These values are representative of Schedule-160 pipe for the diameters of interest. The pressure losses along the hot and cold legs were 0.05 and $0.30 \mathrm{MPa}$ for helium and Flinak, respectively.

The inner diameter of the cold leg, $2 \mathrm{r}_{4}$, was calculated for separation distances between 60 and $500 \mathrm{~m}$. The results of the analyses are presented in Figure 3-16. The largest diameters were obtained when low-pressure helium was the working fluid. The use of high-pressure helium reduced the required diameter by about $20 \%$ regardless of the separation distance. The use of Flinak reduced the required diameter by about $70 \%$ compared to low-pressure helium. An increase in the separation distance from 60 to 500 $\mathrm{m}$ increased the required diameter by about $50 \%$ with all three working fluids. 


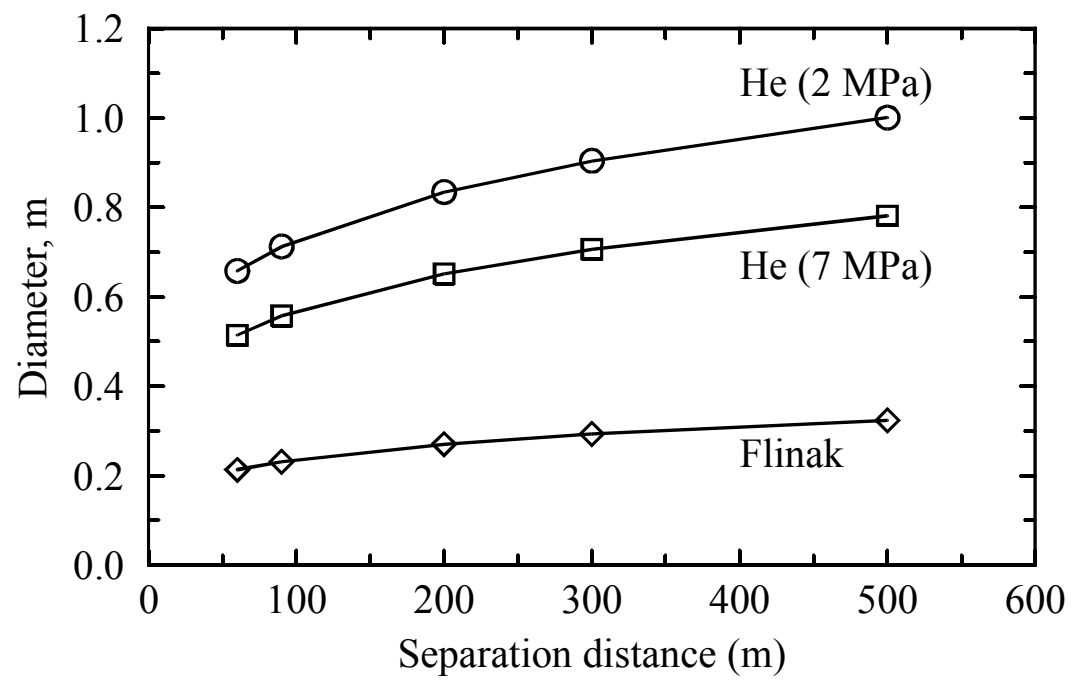

Figure 3-16. The effect of separation distance on cold leg diameter in an annular configuration.

The fluid temperature exiting the IHX and entering the hot leg of the piping, in both configurations, was assumed to be $850^{\circ} \mathrm{C}$. (The focus of the analysis is on the pipe configuration and the energy loss associated with a specific configuration. The details of the IHX and the PHX were not explored here and it was assumed that an IHX could be designed so as to provide hot IHTL fluid at $850^{\circ} \mathrm{C}$.) The temperature of the fluid exiting the PHX was calculated by assuming the PHX deposited 50 MW of thermal energy to the hydrogen production process. The temperature drop across the PHX could then be calculated:

where

$$
\Delta \mathrm{T}=\mathrm{E}_{\mathrm{PHX}} / \mathrm{mC}_{\mathrm{p}} \quad \text { eqn. } 1
$$

$\mathrm{E}_{\mathrm{PHX}}=$ the energy transferred by the PHX, $50 \mathrm{MW}$, in this case

$\mathrm{m}=$ mass flow rate

$\mathrm{C}_{\mathrm{p}}=$ heat capacity of the IHTL fluid

The temperature of the fluid exiting the PHX is then:

where

$$
\mathrm{T}_{\mathrm{n}}(0)=\mathrm{T}_{\mathrm{m}}(\mathrm{L})+\mathrm{E}_{\mathrm{PHX}} / \mathrm{mC}_{\mathrm{p}}
$$

$$
\begin{aligned}
& \mathrm{T}_{\mathrm{n}}(0)=\text { temperature of the IHTL fluid exiting the PHX } \\
& \mathrm{T}_{\mathrm{m}}(\mathrm{L})=\text { temperature of the IHTL fluid entering the PHX } \\
& \mathrm{L} \quad=\text { pipe length }
\end{aligned}
$$

Finally, both pipe configurations were assumed to be immersed in ambient air with an average temperature of $27^{\circ} \mathrm{C}$ and a velocity of $4.5 \mathrm{~m} / \mathrm{s}$. In reality, the IHTL piping would probably be enclosed in a tunnel of some sort with an ambient temperature greater than $27^{\circ} \mathrm{C}$ and an air velocity of less than $4.5 \mathrm{~m} / \mathrm{s}$, but for the current calculation the values used are reasonable. Also the thickness of insulation was adjusted so that the outer temperature of the pipe was on the order of $70^{\circ} \mathrm{C}$ in all the evaluations. (Again, in reality 
temperatures below $50^{\circ} \mathrm{C}$ would probably be more appropriate from a safety standpoint but do not greatly affect the values of heat loss and mean fluid temperature in each leg of the loop.)

Other loop parameters, including the mass flow rate for low (2 $\mathrm{MPa})$ and high (7 MPa) pressure helium and liquid salt, were taken from the Davis, et. al., 2005 report. The helium fluid properties were taken from Tsederberg, et. al., 1971 which provides helium properties as a function of temperature and pressure, and from Davis, 2005 which provides relationships between molten salt properties and temperature. The values used in the calculations have been tabulated in Appendix C.

The temperature profile within the fluids was not of particular importance and only the mean temperature of the fluid as a function of distance was determined. Both pipe configurations yield differential equations describing the mean temperature profiles versus pipe length that are relatively easy to solve in closed form and numerical methods are not required. The derivation of the governing differential equations and their solutions are described in Appendix A for the separate hot and cold pipe configuration and Appendix B for the annular pipe configuration.

\subsubsection{Results}

The results for the separate hot and cold leg configuration are given in Section 3.2.2.1 while the results for the annular design are given in Section 3.2.2.2. The comparison of the two configurations is described in Section 3.2.2.3.

\subsubsection{Separate Hot and Cold Leg Configuration}

The mean temperature of the fluid in both hot and cold legs is an exponentially decreasing function with distance. The mean fluid temperature profile in the hot and cold legs is given by:

$$
\begin{array}{llr}
\text { Hot Leg } & \mathrm{T}_{\mathrm{m}}(\mathrm{x})=\mathrm{T}_{\mathrm{m}, \mathrm{in}} \mathrm{e}^{-\mathrm{Cx}}+\mathrm{T}_{\infty}\left(1-\mathrm{e}^{-\mathrm{Cx}}\right) & \text { eqn. } 3 \\
\text { Cold Leg } & \mathrm{T}_{\mathrm{n}}(\mathrm{x})=\mathrm{T}_{\mathrm{n}}(0) \mathrm{e}^{-\mathrm{Cx}}+\mathrm{T}_{\infty}\left(1-\mathrm{e}^{-\mathrm{Cx}}\right) & \text { eqn. } 4
\end{array}
$$

where

$\mathrm{T}_{\mathrm{m}, \mathrm{in}}=$ the IHX outlet temperature (assumed to be $\mathrm{T}_{\mathrm{m}}(0)=850^{\circ} \mathrm{C}$ )

$\mathrm{T}_{\infty} \quad=$ ambient air temperature (assumed to be $27^{\circ} \mathrm{C}$ )

$\mathrm{C}=$ constant dependent on various loop parameters and is given by:

$$
\mathrm{C}=2 \pi \mathrm{r}_{1} \mathrm{U} /\left(\mathrm{mC}_{\mathrm{p}}\right)
$$

where $U$ describes the overall heat transfer coefficient of the pipe material/insulation system, see Appendix A for more information

$\mathrm{T}_{\mathrm{n}}(0)=$ given by eqn. 2 
The relatively large mass flow rates of the fluids under consideration in combination with the relatively large heat capacities produce a mean fluid temperature profile that is weakly exponential and very nearly linearly decreasing with distance, Figure 3-17.
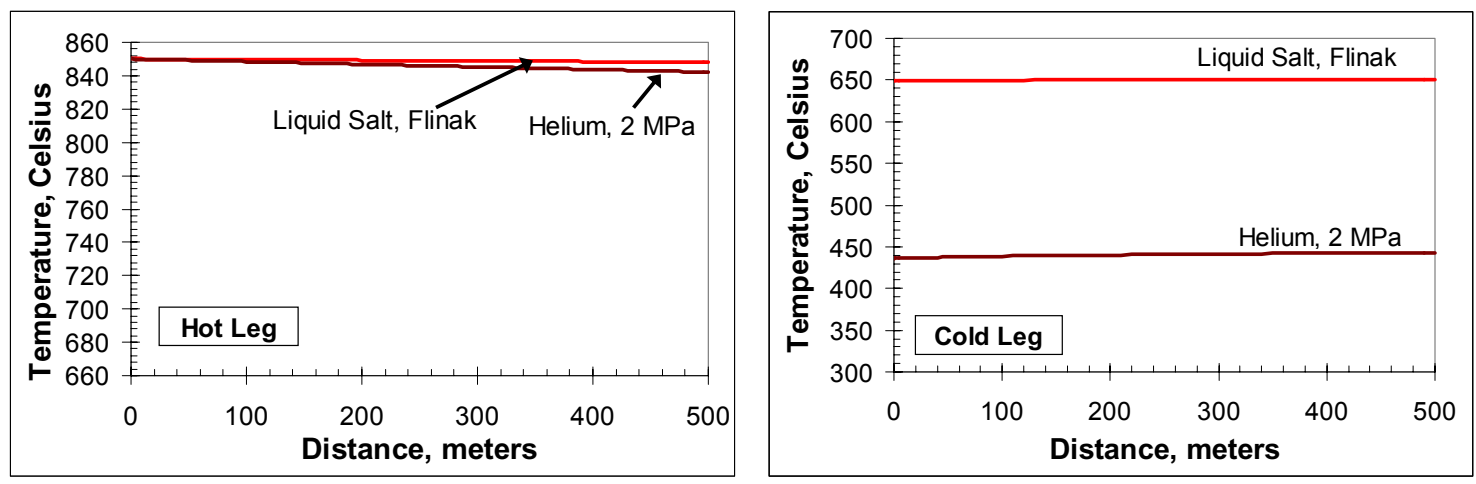

Figure 3-17. Mean fluid temperature as a function of distance along the separate hot and cold legs for a liquid salt (FLiNaK) and low pressure helium (2 MPa). The IHX and $\mathrm{PHX}$ are located at $\mathrm{x}=0$ and $500 \mathrm{~m}$, respectively.

Lowering the product of mass flow rate and heat capacity by a couple of orders of magnitude begins to reveal the exponential relationship between mean fluid temperature and distance. The slope of the temperature profile is small and the temperature change from one end of leg to the other is quite small, even at a distance of 500 meters! Plots of temperature versus distance for all fluids and pipe lengths are all similar to Fig. 3-17 and, therefore, the temperature changes for the various fluids and pipe lengths have been tabulated into Table 3-3. The temperature drop of the hot leg does not exceed $8^{\circ} \mathrm{C}$, even at a 500 meter pipe length.

Table 3-3. Temperature Change for the Separate Leg Pipe Configuration

\begin{tabular}{|c|c|c|c|c|}
\hline & \multicolumn{2}{|c|}{ Temperature Change of Leg, $\Delta \mathrm{T},{ }^{\circ} \mathrm{C}$} & \multirow{2}{*}{$\begin{array}{c}\text { Total Energy } \\
\text { Loss, } \\
\text { Eloss, } \\
\text { MW }\end{array}$} \\
\hline $\begin{array}{l}\text { Heat Transfer } \\
\text { Fluid }\end{array}$ & $\begin{array}{c}\text { Pipe Length, } \\
\text { meters }\end{array}$ & Hot Leg & Cold & \\
\hline \multirow[t]{2}{*}{ Helium, $2 \mathrm{MPa}$} & 90 & 1.13 & 0.96 & 0.26 \\
\hline & 500 & 7.86 & 6.68 & 1.82 \\
\hline \multirow[t]{2}{*}{ Helium, $7 \mathrm{MPa}$} & 90 & 0.97 & 0.81 & 0.22 \\
\hline & 500 & N/E & $\mathrm{N} / \mathrm{E}$ & $\mathrm{N} / \mathrm{E}$ \\
\hline \multirow[t]{2}{*}{ Flinak } & 90 & 0.28 & 0.24 & 0.13 \\
\hline & 500 & 1.97 & 1.68 & 0.92 \\
\hline
\end{tabular}

The energy required by the IHX to account for both the energy drop across the PHX, $\mathrm{E}_{\mathrm{PHX}}$, and to make up the heat loss to the environment is given by: 


$$
\mathrm{E}_{\mathrm{IHX}}=\mathrm{mC}_{\mathrm{p}}\left(\mathrm{T}_{\mathrm{n}}(\mathrm{L})-\mathrm{T}_{\mathrm{m}, \mathrm{in}}\right) \quad \text { eqn. } 5
$$

And the energy loss to the environment is simply:

$$
\mathrm{E}_{\text {loss }}=\mathrm{E}_{\mathrm{IHX}}-\mathrm{E}_{\mathrm{PHX}} \quad \text { eqn. } 6
$$

The total energy lost to the ambient environment is also tabulated in Table 3-3. In all cases the energy lost represents less than $4 \%$ of the total loop energy (50 MW) at a pipe length of 500 meters. The loss drops to less than $0.5 \%$ at a 90 meter pipe length. Use of a molten salt reduces the energy loss to less than $0.3 \%$ and $2 \%$ for pipe lengths of 90 and 500 meters, respectively.

Table 3-4. Insulation Thickness

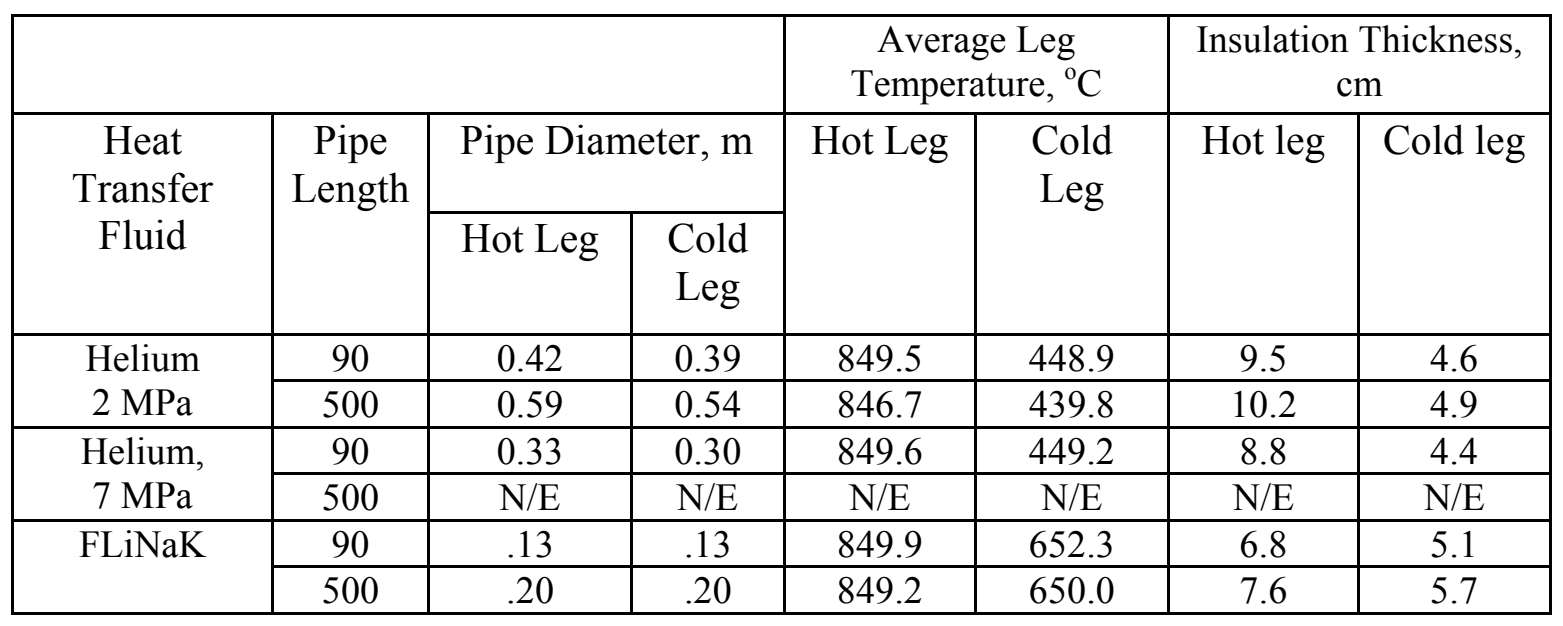

The low values for energy loss are a result of the requirement that the outer surface of both the hot and cold legs be a reasonable temperature, in this case, $72^{\circ} \mathrm{C}$. This value is somewhat arbitrary but has its basis in safety. Insulation is an added cost and therefore the thickness of insulation required to meet the specified surface temperature is tabulated in Table 3-4. The thermal conductivity of the insulation was taken as $0.1 \mathrm{~W} / \mathrm{m} \cdot \mathrm{K}$. This value may be somewhat low and/or relevant to "high" performance insulation which is relatively expensive. Less expensive insulation typically has a higher thermal conductivity and will result in much thicker insulation but the trends shown in Table 3-4 will be similar. The reason for the observed trend in insulation thickness is a result of the pressure drop requirement along each leg (not to exceed $0.05 \mathrm{MPa}$ for helium and 0.30 MPa for liquid salt.

This requirement dictates the pipe diameter, which ultimately determines the energy loss and the amount of insulation required to maintain a reasonable surface temperature. Therefore, high pressure helium requires a smaller diameter pipe compared to low pressure helium at a constant mass flow rate due to increased fluid density. Increasing distances also require larger diameter pipe to maintain the same pressure drop. As the pipe diameter increases more insulation is required to maintain a reasonable surface 
temperature. The hot leg of the liquid salt pipe requires less insulation than the helium options due to its very high density (and moderate heat capacity) compared to helium and, therefore, requires a smaller pipe diameter. The cold leg of the liquid salt pipe requires more insulation than the cold leg of the helium option because the higher temperature of the "cold" liquid salt $\left(\sim 650^{\circ} \mathrm{C}\right)$ compared to the "cold" helium $\left(\sim 450^{\circ} \mathrm{C}\right)$, Table 4 and Fig. 18, even though the pipe diameter is smaller for the liquid salt option.

Finally, it should be noted that the "cold" leg of the liquid salt option is well above the freezing temperature of Flinak $\left(\sim 454^{\circ} \mathrm{C}\right)$. Even though other liquid salts (e.g. $\mathrm{NaBF}_{4}$ $\mathrm{NaF}$, etc.) have slightly different thermal and physical properties they will probably be suitable (i.e. will not freeze) for use in the IHTL. However, the thermal analysis should be performed to confirm their suitability.

\subsubsection{Annular Pipe Design}

The annular pipe design possesses advantages over the separate hot and cold leg option. Specifically, heat lost by the hot leg is recovered by the cold leg instead of being lost to the environment. Substantial energy savings are expected with the annular design. Also, the cold fluid acts to reduce the temperature of the inner pipe material, thereby reducing the creep potential. The creep potential is also lowered (almost negated) since the pressure differential across inner hot pipe is almost zero. The cold pipe acts as the pressure boundary and since it is at a much lower temperature the number of pipe materials that can be used is much greater. The disadvantage of the annular pipe design is the higher fabrication and maintenance costs.

The relationship for the mean fluid temperature of the hot leg is very similar to the hot leg of the separate leg configuration. However, the relationship for the mean fluid temperature of the cold leg is significantly different and arises due to the heat transferred from the hot pipe to the cold fluid. Expressions for the hot and cold temperature profiles are given below (see Appendix B):

$$
\begin{array}{lr}
\mathrm{T}_{\mathrm{m}}(\mathrm{x})=\mathrm{G}_{1} \mathrm{e}^{-\mathrm{Mx}}+\mathrm{G}_{2} \mathrm{e}^{-\mathrm{Nx}}+\mathrm{C} / \mathrm{C}_{3} & \text { eqn. } 7 \\
\mathrm{~T}_{\mathrm{n}}(\mathrm{x})=\mathrm{G}_{1}\left(1-\mathrm{C}_{1} \mathrm{M}\right) \mathrm{e}^{-\mathrm{Mx}}+\mathrm{G}_{2}\left(1-\mathrm{C}_{1} \mathrm{~N}\right) \mathrm{e}^{-\mathrm{Nx}}+\mathrm{C} / \mathrm{C}_{3} & \text { eqn. } 8
\end{array}
$$

(The constants $\mathrm{G}_{1}, \mathrm{G}_{2}, \mathrm{M}, \mathrm{N}, \mathrm{C}_{1}, \mathrm{C}_{3}$ and $\mathrm{C}$ are all dependent on fluid properties, mass flow rate, etc. See Appendix B for a complete explanation of the derivation and definition of the constants.) Again, both temperature profiles are exponential in nature. As with the separate hot and cold leg configuration the mass flow rate and the heat capacity of the fluids are such as to produce a weak exponential relationship (again, nearly linear), Figure 3-18. However, the temperature of the cold fluid increases as it travels back to the IHX, while the temperature continues to decrease in the separate hot and cold leg configuration, Figure. 3-17. The temperature drop for the hot leg is on the order of $58.9^{\circ} \mathrm{C}$ for helium and $29.9^{\circ} \mathrm{C}$ for the liquid salt while the temperature increases of the cold legs are 48.3 and $27.5^{\circ} \mathrm{C}$, respectively. The reason for the large temperature drops are a result of the relatively thin insulation layer around the inner hot pipe $(5.5 \mathrm{~mm}$ for the helium and $0.8 \mathrm{~mm}$ for the liquid salt). The choice of insulation layer thickness is 
somewhat arbitrary at this point. Increasing the insulation thickness will reduce the temperature change. Since the heat loss from the hot pipe is transferred to the cold fluid and not lost to the ambient environment the insulation layer was kept to a minimum. Probably a better option would be to apply a thermal barrier coating to the inside of the hot pipe, instead of applying insulation to the outside of the hot pipe. The plots in Figure 3-19 were generated by assuming the insulation was on the inside of the inner pipe (not the outside of the inner pipe as in Figure 3-18). Various parameters also have been tabulated in Table 5 for the two different configurations for comparison purposes. The difference in average fluid temperature for the hot and cold legs is not that great, although the temperatures of the insulation/pipe configuration are slightly higher and the temperature change from one end of the pipe to the other is lower. This is a direct result of the lower heat transfer from the hot pipe to the cold fluid, shown as the energy loss from the hot pipe in Table 3-5.
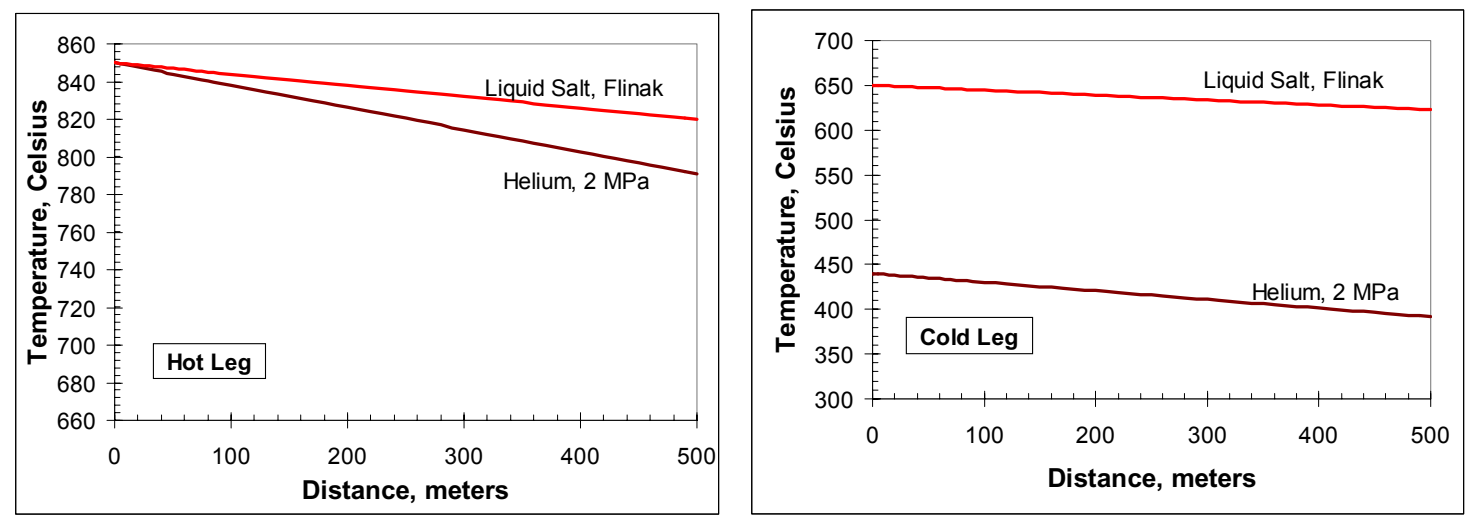

Figure 3-18. The temperature profile of the hot and cold legs for the annular design with $500 \mathrm{~m}$ separation distance and insulation on the exterior of the inner pipe. The IHX and $\mathrm{PHX}$ are located at $\mathrm{X}=0$ and $500 \mathrm{~m}$, respectively.
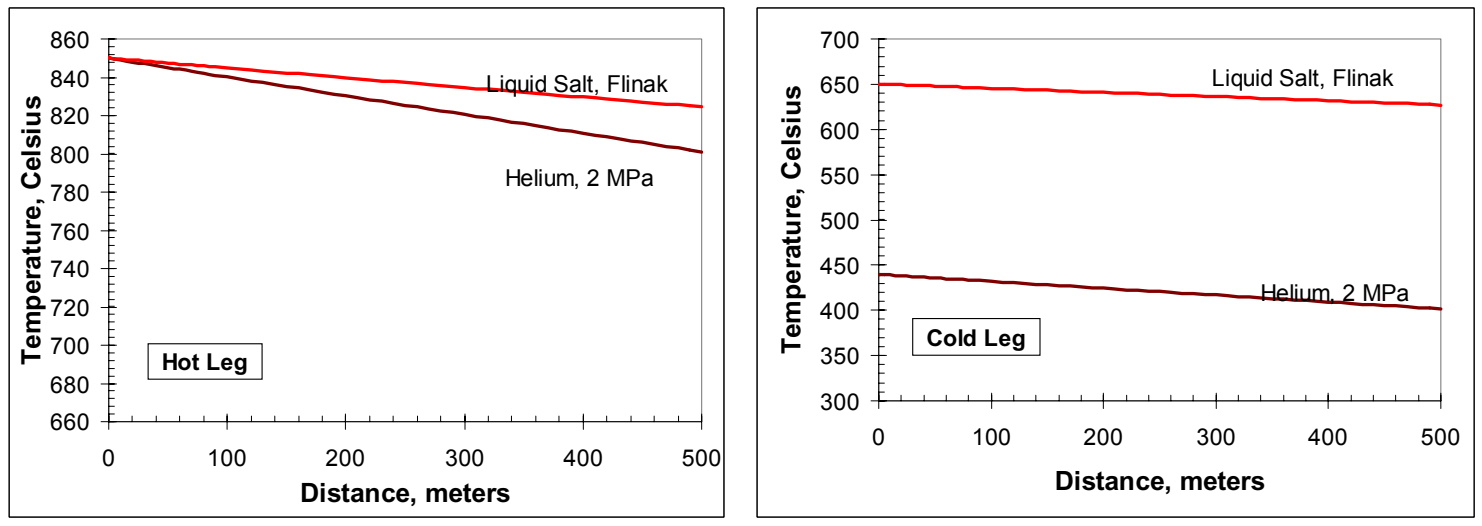

Figure 3-19. The temperature profile of the hot and cold legs for the annular design with a $500 \mathrm{~m}$ separation distance and insulation on the interior of the inner pipe. The IHX and $\mathrm{PHX}$ are located at $\mathrm{X}=0$ and $500 \mathrm{~m}$, respectively.

The most dramatic and important difference is in the inner pipe wall temperature. When the insulation is placed on the outside of the hot pipe, the pipe wall temperature is in 
excess of $800^{\circ} \mathrm{C}$ for both low pressure helium and liquid salt. However, by applying the same thin layer $(5.5 \mathrm{~mm})$ of insulating material to the interior of the hot pipe, the hot pipe wall temperature is decreased to less than $700^{\circ} \mathrm{C}$ for liquid salt, Table $3-5$, and less than $500^{\circ} \mathrm{C}$ for low pressure helium (not shown in Table 3-5). Again, the thermal conductivity of this interior pipe insulation was assumed to be $0.1 \mathrm{~W} / \mathrm{m} \cdot{ }^{\circ} \mathrm{C}$., which is probably low for a thermal barrier coating. These temperatures are well within the operational limits of much less exotic/expensive materials than I-800H or I-617. By reducing the inner pipe temperature the creep potential of the inner pipe is reduced and the design stress may be increased, resulting in thinner pipe walls and decreased costs. (The ASME Boiler and Pressure Vessel Code, allowable design stress increases from $\sim 10 \mathrm{MPa}$ at $850^{\circ} \mathrm{C}$ to $\sim 100$ $\mathrm{MPa}$ at $650^{\circ} \mathrm{C}$, [Special Metals, 2005].) Thermal barrier coating are routinely used in aircraft engines and are probably ideal for the IHTL pipes. Finally, it should be mentioned that a thermal barrier coating could also be applied to the separate hot/cold leg design with similar benefits.

Table 3-5. Effect of Hot Pipe Insulation Configuration on Pipe Temperatures*

\begin{tabular}{|l|c|c|c|}
\hline Parameter & $\begin{array}{c}\text { Pipe/Insulation } \\
\text { Configuration }\end{array}$ & $\begin{array}{c}\text { Insulation/Pipe } \\
\text { Configuration }\end{array}$ \\
\hline \multirow{2}{*}{$\begin{array}{l}\text { Average Leg } \\
\text { Temperature }\end{array}$} & Hot Leg & 837.5 & 839.3 \\
\cline { 2 - 4 } $\begin{array}{l}\text { Temperature change } \\
\text { over pipe length, } \Delta \mathrm{T}, \\
{ }^{\circ} \mathrm{C}\end{array}$ & Cold Leg & 638.7 & 640.6 \\
\cline { 2 - 4 } $\begin{array}{l}\text { Average Hot Pipe } \\
\text { Wall Temperature, }{ }^{\circ} \mathrm{C}\end{array}$ & Cold Leg & -29.9 & -25.5 \\
\cline { 2 - 4 } & Onner Pipe Surface & 83.5 & 23.0 \\
\hline $\begin{array}{l}\text { Average Cold Pipe } \\
\text { Wall Temperature, }{ }^{\circ} \mathrm{C}\end{array}$ & Inner Pipe Surface & 813.6 & 671.4 \\
\cline { 2 - 4 } & Outer Pipe Surface & 637.9 & 655.1 \\
\hline Energy Lost by the Hot Pipe, MW & 737.0 & 626.4 \\
\hline \multicolumn{2}{|l|}{ Total Energy Loss to the Environment, MW } & 0.62 & 6.4 \\
\hline
\end{tabular}

\subsubsection{Comparison of IHTL Pipe Designs}

In comparing the different pipe designs there are three aspects to consider:

1. Hot fluid delivery temperature to the PHX

2. Energy loss to the ambient environment

3. Cost, including raw materials (pipe and insulation) and fabrication costs.

The first point is critical to the hydrogen production process that is being powered by the nuclear heat source. The second point relates to the economics and the efficiency of the entire process. The third point determines the capital investment. 


\section{Hot Fluid Delivery Temperature}

Table 6 shows the fluid temperature delivered to the PHX for each of the pipe design options. For the most part all the designs are capable of delivering the IHTL fluid to the PHX at a temperature $\left(\geq 800^{\circ} \mathrm{C}\right)$ suitable for the various hydrogen production processes, whether it be high temperature electrolysis or thermochemical hydrogen. The insulation thickness (or a more complicated configuration, e.g. insulation/pipe/insulation configuration) could be used to increase the fluid temperature for the $2 \mathrm{MPa}$ helium in the 500 meter annulus design to meet the temperature requirement. Therefore, this parameter will not be of prime concern when choosing a particular pipe design, other than how it relates to the amount (and cost) of insulation.

Table 3-6. Comparison of Pipe Configurations

\begin{tabular}{|c|c|c|c|c|c|}
\hline & $\begin{array}{l}\text { Pipe } \\
\text { Length, } \\
\text { meters }\end{array}$ & Fluid & $\begin{array}{l}\text { Separate } \\
\text { hot/cold leg } \\
\text { configuration }\end{array}$ & $\begin{array}{l}\text { Annulus - } \\
\text { Pipe/insulation } \\
\text { configuration }\end{array}$ & $\begin{array}{l}\text { Annulus - } \\
\text { Insulation/pipe } \\
\text { configuration }\end{array}$ \\
\hline \multirow{5}{*}{$\begin{array}{l}\text { Temperature } \\
\text { of Fluid } \\
\text { Delivered to } \\
\text { PHX }\end{array}$} & \multirow[t]{3}{*}{90} & $\mathrm{He}, 2 \mathrm{MPa}$ & 848.9 & 842.1 & $\mathrm{~N} / \mathrm{E}$ \\
\hline & & $\mathrm{He}, 7 \mathrm{MPa}$ & 849.0 & 843.7 & $\mathrm{~N} / \mathrm{E}$ \\
\hline & & FLiNaK & 849.7 & 846.1 & $\mathrm{~N} / \mathrm{E}$ \\
\hline & \multirow[t]{2}{*}{500} & $\mathrm{He}, 2 \mathrm{MPa}$ & 842.1 & 791.1 & 801.1 \\
\hline & & FLiNaK & 848.0 & 820.1 & 824.5 \\
\hline \multirow{5}{*}{$\begin{array}{l}\text { Total } \\
\text { Energy Lost } \\
\text { to the } \\
\text { Environment }\end{array}$} & \multirow[t]{3}{*}{90} & $\mathrm{He}, 2 \mathrm{MPa}$ & 0.26 & 0.19 & $\mathrm{~N} / \mathrm{E}$ \\
\hline & & $\mathrm{He}, 7 \mathrm{MPa}$ & 0.22 & 0.16 & $\mathrm{~N} / \mathrm{E}$ \\
\hline & & FLiNaK & 0.13 & 0.09 & $\mathrm{~N} / \mathrm{E}$ \\
\hline & \multirow{2}{*}{500} & $\mathrm{He}, 2 \mathrm{MPa}$ & 1.82 & 1.33 & 1.35 \\
\hline & & FLiNaK & 0.92 & 0.62 & 0.63 \\
\hline
\end{tabular}

\section{Energy Loss to the Ambient Environment}

The energy lost from the IHTL to the environment will enter into the calculation of efficiency of the overall hydrogen production process, with large losses obviously lowering the overall efficiency of hydrogen production from nuclear heat and raising the cost of the hydrogen product. Table 3-6 shows significant differences in energy loss between the different pipe configurations. The separate hot/cold leg configuration exhibits the greatest energy losses compared to the annulus designs. This is due to the fact that heat is lost through the surface of both the hot and cold pipes while, in the annulus design, heat is lost to the environment only through the outer, cold pipe. The energy lost by the annulus configuration is approximately $27 \%$, in the case of helium, and $30 \%$, in the case of liquid salt, less than that of the separate hot/cold leg design. The use of liquid salt decreases the energy loss by approximately $50 \%$ and $40 \%$ over low ( $2 \mathrm{MPa}$ ) and high (7 MPa) helium, respectively. However, the effect of applying a thermal barrier coating to the interior of the pipes in the separate hot/cold leg design needs to be evaluated. The expectation is that energy losses will be dramatically reduced but will still be higher than the annulus configuration.

Cost 
An in depth analysis of the costs related to the different configurations was not undertaken in this work. However, areas where cost savings can be realized are readily apparent. The use of pressurized helium requires relatively thick-walled pipe of advanced alloys with outstanding high temperature properties. In the case of high pressure helium (7 $\mathrm{MPa}$ ) the wall thickness exceeds standard pipe wall thickness to diameter ratios and therefore the pipe would be a special order item. In this regard, IHTL piping for helium would be costly.

Conversely, the annulus design inherently lowers the creep potential by reducing the pressure differential across the hot pipe wall. Furthermore, the insulation/pipe annulus design also exhibits a much lower hot pipe wall temperature, allowing the use of less expensive alloys and allowing the design stress to be increased, thereby reducing pipe wall thickness, both of which reduce the overall cost of the IHTL piping. However, fabrication costs will probably be greater. No manufacturer of high temperature, annular pipe designs could be found and, therefore, this also would be a specialty product. Also the cost of applying the thermal barrier coating must be considered. Maintenance costs may also be substantially more for this design since problems with the inner hot piper, where problems are most likely to occur, would require disassembly. The separate hot/cold leg design could be repaired simply by welding on the outside of the pipe.

\subsubsection{Conclusions}

The major conclusion found in this analysis is that transport of nuclear heat, whether it is over 90 meters or even 500 meters, probably will not be a difficult problem to solve. It would appear that molten salt with an annular design would provide the best option based on delivery temperature and energy loss considerations. However, a comparison of each design with optimized parameters for each design is still required. The differences highlighted here may be significantly reduced through optimization of each configuration and the final choice could depend mainly on costs involved with fabrication and maintenance. Also further investigations into thermal barrier coatings and the advantages and disadvantages they pose are needed.

\subsection{Process Heat Exchanger Analysis}

Up to this point the intermediate heat exchanger has received the attention of research and development efforts. However, the process heat exchanger (PHX) also has serious engineering challenges associated with it. Based on the thermal analysis of Section 3.2, the PHX will operate at temperatures only slightly lower than those of the IHX. Furthermore the PHX will be exposed to highly corrosive environments, in the case of the thermochemical hydrogen production processes. Therefore the PHX will have to have exceptional corrosion resistance as well as exceptional high temperature mechanical properties. 
The design of the PHX has been a point of contention in the past. Traditionally, chemical processes that require the use of a catalyst have utilized a packed bed, tubes in shell type heat exchanger/reactor. However, previous reports by General Atomics [Brown, et.al, June 2003] indicate a preference for the compact heat exchanger/reactor design, much like the Heatric printed circuit-type heat exchanger (PCHE). In this case the catalyst would be applied to the walls of the channels carrying the process fluids. It has been pointed out by chemical engineers that the surface area of a packed bed probably is much greater than the surface area of a compact heat exchanger.

Therefore a simple qualitative analysis of the surface area available for catalytic reactions for the packed bed type reactor and the Heatrics type microchannel reactor was undertaken.

\section{Packed-Bed, Tubes-in-Shell Type Reactor}

The tubes in shell type reactor/heat exchanger was evaluated in the report by Davis, et.al, 2005. The analysis was based on purely heat transfer and the analysis did not assume the tubes were packed with the catalyst, i.e. the tubes only contained the process fluid. In reality the catalyst is coated on to the internal surface area of small porous beads or other substrate forms that are then packed into the tubes of the reactor. As a result the size and number of tubes in a packed-bed tubes in shell reactor may be significantly different than in the analysis by Davis, et.al, 2005. However, this simple analysis will use the results given in that report.

The tubes in shell PHX outlined by Davis, et. al, 2005 consists of 3320 tubes that are 1 $\mathrm{cm}$ in diameter and 10.2 meters long. This was deemed sufficient for a thermochemical process receiving 50MW thermal from the IHTL. This provides a volume of $2.66 \mathrm{~m}^{3}$ for the catalyst inside the process tubes. Work by Dr. Daniel Ginosar and co-workers at the INL have found that a weight hourly space velocity (WHVS) of about 10 grams sulfuric acid/ gram of catalyst / hour is necessary to provide near equilibrium conversion levels $\left(2 \mathrm{H}_{2} \mathrm{SO}_{4} \rightarrow 2 \mathrm{SO}_{2}+2 \mathrm{H}_{2} \mathrm{O}+\mathrm{O}_{2}\right)$ of $62 \%$ for catalyst containing $0.1 \mathrm{wt} \%$ platinum on a titanium dioxide support. According to the 2003 GA report [Brown, et. al., 2003] a 50 MW sulfur-iodine thermochemical system would feed 49,600 kg/hour into the PHX. This would require $4,960 \mathrm{~kg}$ of catalyst $\left(0.1 \mathrm{wt} \% \mathrm{Pt}\right.$ on $\left.\mathrm{TiO}_{2}\right)$. The packed bed density of the catalyst was found to be on the order of $1.42 \mathrm{~g} / \mathrm{cm}^{3}$ with a void volume of approximately $42 \%$ (the catalyst pieces themselves have a density of $2.45 \mathrm{~g} / \mathrm{cm}^{3}$ ). Therefore, $4,960 \mathrm{~kg}$ of catalyst would require $3.47 \mathrm{~m}^{3}$, using the packed density given above. This is on the same order of magnitude as the volume available for catalyst in the PHX $\left(2.66 \mathrm{~m}^{3}\right)$ given by Davis, et. al. However, it would appear from this simple analysis that the design of a tubes-in-shell type PHX may be driven by catalyst requirements as opposed to thermal requirements.

\section{PCHE - type PHX/Reactor}

In the PCHE design the catalyst is applied to the surfaces of the process channels. Therefore the surface area of the process channels in a PCHE type heat exchanger must be calculated. A design specifically for the PHX of the sulfuric acid decomposition 
reaction could not be found in literature. Therefore it was assumed that the PHX would look very much like the IHX which is given in the report by Davis, et. al, 2005. This is justified in this simple analysis since the operating temperatures of both the IHX and the PHX are similar and both will deposit the same amount of thermal energy to another fluid, helium in the case of the IHX and sulfuric acid vapors in the case of the PHX.

A schematic of the reactor channel design is shown in Figure 4. The pitch to diameter ratios of $\mathrm{p} / \mathrm{d}=1.5$ and $\mathrm{t}_{\mathrm{p}} / \mathrm{d}=0.78$ are taken from Table 1 for the pressure conditions, $\mathrm{P}_{\mathrm{i}} /$ $\mathrm{P}_{\mathrm{o}}$, of $7 \mathrm{MPa} / 2 \mathrm{MPa}$. The size of the IHX given in the report by Davis, et. al., 2005 is $2.37 \mathrm{~m} \times 2.33 \mathrm{~m} \times 0.076 \mathrm{~m}$. If the channel diameter is assumed to be $1 \mathrm{~mm}$ (and all channels identical) the number of channels in a $2.33 \mathrm{~m} \times 2.37 \mathrm{~m}$ reactor is $4.7 \times 10^{6}$. Based on the semi-circular design shown in Figure 3-3, the total surface area of the process channels is on the order of $500 \mathrm{~m}^{2}$. The catalyst used by researchers at the INL has a platinum surface area of $0.0316 \mathrm{~m}^{2} /$ gram of $0.1 \mathrm{wt} \% \mathrm{Pt}$ on $\mathrm{TiO}_{2}$ catalyst. Thus, the $4,960 \mathrm{~kg}$ of catalyst required to produce equilibrium conversion for a $50 \mathrm{MW}$ sulfuric decomposition process contains approximately $157,000 \mathrm{~m}^{2}$ of platinum surface area that is available for catalysis! In order to achieve this amount of surface area the Heatrics type reactor would have to be approximately 26 meters long (only half of the channels in the Heatrics reactor are process channels - the others are for the IHTL fluid), making it larger than the shell and tube type reactor. Table 3-7 shows the effect of reducing the channel diameter on the length of the reactor. Obviously, the channel diameter must be on the order of $0.1 \mathrm{~mm}$ or less to provide the required amount of platinum surface in a compact design.

Such a small channel diameter $(100 \mu \mathrm{m})$ would be prone to plugging by corrosion products and/or other impurities. The above analysis assumes a continuous layer of platinum applied to the walls of the process channels. There are indications that catalysis occurs mainly at the catalyst support/metal interface and at defects in the platinum. A continuous layer of catalyst metal probably has a much lower catalytic activity than when applied to a porous support. Therefore the size of a PCHE-type reactor would be even greater than that calculated here. An alternative would be to apply a wash containing catalyst support particles coated with the platinum catalyst. It is difficult to estimate how this methodology would affect the size of the PCHE-type reactor. However, it can be concluded from this simple analysis that the design of the PCHE-type reactor will be based on the catalytic requirements rather than the thermal requirements.

Furthermore, this simple analysis suggests that further research on the PHX is desperately needed to make an informed decision on the final PHX design. 
Table 3-7. Length of PCHE-type Reactor

\begin{tabular}{|c|c|c|c|c|c|c|}
\hline $\begin{array}{c}\text { Channel } \\
\text { Diameter, } \\
\mathrm{m}\end{array}$ & Pitch, $\mathrm{m}$ & $\begin{array}{c}\text { Through } \\
\text { Thickness } \\
\text { pitch, } \mathrm{t}_{\mathrm{p}}, \mathrm{m}\end{array}$ & $\begin{array}{c}\text { \# of Tubes } \\
\text { Across HX } \\
\text { Face }\end{array}$ & $\begin{array}{c}\text { \# of Tubes } \\
\text { Through } \\
\text { Thickness }\end{array}$ & $\begin{array}{c}\text { total \# of } \\
\text { tubes }\end{array}$ & $\begin{array}{c}\text { Reactor } \\
\text { Length, } \mathrm{m}\end{array}$ \\
\hline 0.001 & 0.0015 & 0.00078 & 1580 & 2987 & $2.4 \mathrm{E}+06$ & 25.9 \\
\hline 0.0005 & 0.00075 & 0.00039 & 3160 & 5974 & $9.4 \mathrm{E}+06$ & 12.9 \\
\hline 0.0001 & 0.00015 & 0.000078 & 15800 & 29871 & $2.36 \mathrm{E}+08$ & 2.6 \\
\hline
\end{tabular}




\section{SUMMARY}

\subsection{Intermediate Heat Exchanger Stress Analysis}

The stress analysis of the IHX shows that there are serious materials issues associated with this component. The pressure differential between the primary coolant from the nuclear power plant and the fluid in the IHTL gives rise to significant stresses within the printed circuit heat exchanger (PCHE) design and failure is predicted in many cases currently under consideration.

- Variation of pressure of the IHTL fluid between 0 and $5 \mathrm{MPa}$ results stresses in a PCHE made of Alloy I-617 that exceed the expected allowable stress when the primary coolant pressure is $7 \mathrm{MPa}$ and no external pressure is applied to the PCHE.

- Immersion of the PCHE in a pressurized environment at $7 \mathrm{MPa}$ reduces the stress within the PCHE to acceptable levels as long as the IHTL fluid pressure does not fall below $3 \mathrm{MPa}$.

- Other materials, possibly ceramics, with higher creep strength at the operating temperature may enable the use of compact heat exchangers like the PCHE.

- An alternate PCHE design may alleviate the stresses to acceptable levels but the efficiency may be lower than that of the PCHE.

\section{Thermal Analysis of the IHTL Pipe Configuration}

Two different pipe configurations for transporting the IHTL fluid were evaluated. The baseline configuration is separate supply and return pipes wrapped with insulation. The second configuration consisted of an annular design with the hot fluid (supply) flowing through the center and the cold (return) fluid flowing in the annular space surrounding the hot pipe.

- The mean temperature profile of both configurations is exponentially decreasing with distance.

- The high flow rates and high heat capacities of the fluids result in only small temperature drops for all configurations, even for pipe lengths of 500 meters.

- All configurations are capable of delivering energy to the PHX at temperatures in excess of $800^{\circ} \mathrm{C}$.

- Energy loss to the environment is less than $4 \%$ of the loop power in all cases.

- Liquid salt heat transfer fluids maintain higher temperatures and exhibit less heat loss ( $\sim 50 \%$ less $)$ to the environment compared to low and high pressure helium.

- The annular design generally exhibits lower energy losses.

- Thermal barrier coating may be highly useful in all the designs by lowering heat loss and pipe wall temperature.

- Each pipe configuration needs to be optimized individually.

- Costs (both fabrication and maintenance) associated with each design need to be investigated. 


\section{Process Heat Exchanger Analysis}

The process heat exchanger must not only transfer energy from the IHTL fluid to the process fluid but it also acts as the decomposition reactor for the decomposition of sulfuric acid vapors over a catalyst. A PCHE with the catalyst applied to the process channel walls has been suggested for this process step. The size of a PCHE with the necessary catalytic surface area is calculated and compared to a conventional tube in shell type reactor.

- The tube in shell reactor with a packed bed of catalyst would be a little over 10 meters long and occupy a volume of a little over $9 \mathrm{~m}^{3}$.

- The PCHE with catalyst applied to the process channel walls would have to be $\sim 26$ meters long if the channels were $1 \mathrm{~mm}$ in diameter. It would occupy a volume of $144 \mathrm{~m}^{3}$.

- Alternate catalyst incorporation into the PCHE design is needed to keep the unit small.

- $\mathrm{R} \& \mathrm{D}$ on the PHX is desperately needed. 


\section{REFERENCES}

Brown, L.C, Besenbruch, G.E., Lentsch, R.D., Schultz, K.R., Funk, J.F., Pickard, P.S., Marshall, A.C., Showalter, S.K., "High Efficiency Generation of Hydrogen Fuels Using Nuclear Power", General Atomics Report GA-A24285, June, 2003.

Davis, C.B., 2005, "Implementation of Molten Salt Properties into RELAP5-3D/ATHENA", INL/EXT - $05-02658$, January.

Davis, C.B. Oh, C.H, Barner, R.B. and Wilson, D.F, 2005, "Thermal-Hydraulic Analyses of Heat Transfer Fluid Requirements and Characteristics for Coupling a Hydrogen Production Plant to a High-Temperature Nuclear Reactor", INL/EXT - 05 - 00453, June.

Independent Technology Review Group, 2004, "Design Features and Technology Uncertainties for the Next Generation Nuclear Plant," INEEL/EXT-04-01816.

Smith, C., S. Beck, and B. Galyean, 2005, “An Engineering Analysis for Separation Requirements of a Hydrogen Production Plant and High-Temperature Nuclear Reactor," INL/EXT-05-00137 Rev 0, March.

Special Metals Corporation, “Inconel alloy 617”, Publication Number SMC-029, 2005.

Tsederberg, N.V., Popov, V.N., and Morozova, N.A., Thermodynamic and Thermophysical Properties of Helium, edited by A.F. Alyab'ev, Israel Program for Scientific Translations, Keter Press, Jerusalem, 1971. 


\section{Appendix A. Thermal Analysis of Separate Hot/Cold Pipe Design}
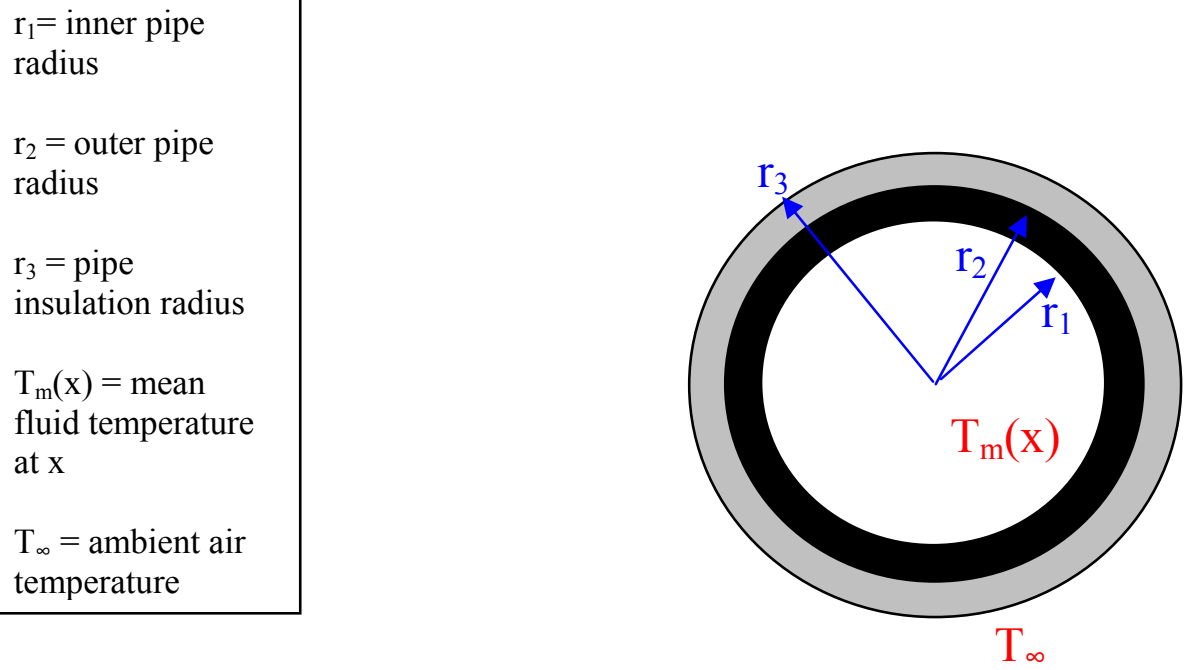

The figure above represents the cross section of an insulated pipe with fluid flowing through the center at a mass flow rate of $\mathrm{m}$. The pipe is immersed in an environment of constant temperature, $T_{\infty}$. The mean temperature of the fluid as a function of distance along the pipe is given by $\mathrm{T}_{\mathrm{m}}(\mathrm{x})$.

Assuming the flow work is negligible, the energy balance on a differential length of the above cross section is given by:

$$
\mathrm{mC}_{\mathrm{p}} \mathrm{dT}_{\mathrm{m}}(\mathrm{x})=2 \pi \mathrm{r}_{1} \mathrm{dx} \cdot \mathrm{U} \cdot\left(\mathrm{T}_{\infty}-\mathrm{T}_{\mathrm{m}}(\mathrm{x})\right) \quad \text { eqn. A1a }
$$

or

$$
\mathrm{dT}_{\mathrm{m}}(\mathrm{x}) / \mathrm{dx}=2 \pi \mathrm{r}_{1} \mathrm{U} /\left(\mathrm{mC}_{\mathrm{p}}\right) \cdot\left(\mathrm{T}_{\infty}-\mathrm{T}_{\mathrm{m}}(\mathrm{x})\right) \quad \text { eqn. } \mathrm{A} 1 \mathrm{~b}
$$

where

$\mathrm{U}=$ the overall heat transfer coefficient and:

$$
\mathrm{U}=\left(1 / \mathrm{h}_{1}+\mathrm{r}_{1} / \mathrm{k}_{1} \cdot \operatorname{Ln}\left(\mathrm{r}_{2} / \mathrm{r}_{1}\right)+\mathrm{r}_{1} / \mathrm{k}_{2} \cdot \operatorname{Ln}\left(\mathrm{r}_{3} / \mathrm{r}_{2}\right)+\mathrm{r}_{1} /\left(\mathrm{r}_{3} \mathrm{~h}_{3}\right)\right)^{-1}
$$

$\mathrm{C}_{\mathrm{p}}=$ heat capacity of the fluid

$\mathrm{h}_{1}=$ heat transfer coefficient between the fluid and the inner pipe surface at $\mathrm{r}_{1}$

$h_{3}=$ heat transfer coefficient between the surface at $r_{3}$ and the ambient environment 


$$
\mathrm{k}_{\mathrm{i}}=\text { thermal conductivity of layer } \mathrm{i}
$$

Defining $\mathrm{C}$ as:

$$
\mathrm{C}=2 \pi \mathrm{r}_{1} \mathrm{U} /\left(\mathrm{mC}_{\mathrm{p}}\right)
$$

Then eqn. A1b becomes:

or

$$
\mathrm{dT}_{\mathrm{m}}(\mathrm{x}) / \mathrm{dx}=\mathrm{C} \cdot\left(\mathrm{T}_{\infty}-\mathrm{T}_{\mathrm{m}}(\mathrm{x})\right) \quad \text { eqn. } \mathrm{A} 3 \mathrm{a}
$$

$$
\mathrm{dT}_{\mathrm{m}}(\mathrm{x}) / \mathrm{dx}+\mathrm{CT}_{\mathrm{m}}(\mathrm{x})=\mathrm{CT}_{\infty}
$$

The differential equation in eqn. A3b can be solved using an integrating factor, $\mathrm{e}^{\mathrm{Cx}}$. So multiplying both sides of eqn. A3B:

$$
\mathrm{e}^{\mathrm{Cx}}\left(\mathrm{dT}_{\mathrm{m}}(\mathrm{x}) / \mathrm{dx}+\mathrm{CT}_{\mathrm{m}}(\mathrm{x})\right)=\mathrm{CT}_{\infty} \mathrm{e}^{\mathrm{Cx}}
$$

which is equivalent to:

$$
\mathrm{d} / \mathrm{dx}\left(\mathrm{e}^{\mathrm{Cx}} \cdot \mathrm{T}_{\mathrm{m}}(\mathrm{x})\right)=\mathrm{CT} \mathrm{T}_{\infty} \mathrm{e}^{\mathrm{Cx}}
$$

Integrating along the pipe length:

$$
\int_{0}^{x}\left(d / d x\left(e^{C x} \cdot T_{m}(x)\right)\right) d x=\int_{0}^{x} C T_{\infty} e^{C x} d x \quad \text { eqn. A5c }
$$

Or

$$
\mathrm{e}^{\mathrm{Cx}} \cdot \mathrm{T}_{\mathrm{m}}(\mathrm{x})-\mathrm{e}^{0} \cdot \mathrm{T}_{\mathrm{m}}(0)=\mathrm{T}_{\infty}\left(\mathrm{e}^{\mathrm{Cx}}-1\right) \quad \text { eqn. } \mathrm{A} 5 \mathrm{~b}
$$

Rearranging:

$$
\mathrm{T}_{\mathrm{m}}(\mathrm{x})=\mathrm{T}_{\mathrm{m}}(0) \mathrm{e}^{-\mathrm{Cx}}+\mathrm{T}_{\infty}\left(1-\mathrm{e}^{-\mathrm{Cx}}\right) \quad \text { eqn, } \mathrm{A} 6
$$

The value of $\mathrm{T}_{\mathrm{m}}(0)$ is taken as the temperature of the fluid entering the pipe and is known, as are the other constants in eqn. A6.

The values of temperature at each surface (corresponding to $r_{1}, r_{2}$ and $r_{3}$ ) are given by:

$$
\begin{array}{lr}
\mathrm{T}_{1}=\mathrm{T}_{\mathrm{m}}(\mathrm{x})+\mathrm{U}_{\mathrm{in}} / \mathrm{h}_{1}\left(\mathrm{~T}_{\infty}-\mathrm{T}_{\mathrm{m}}(\mathrm{x})\right) & \text { eqn. } \mathrm{A} 7 \mathrm{a} \\
\mathrm{T}_{2}=\mathrm{T}_{1}(\mathrm{x})+\mathrm{r}_{1} \mathrm{U}_{\mathrm{in}} / \mathrm{k}_{\mathrm{p}, \mathrm{in}} \operatorname{Ln}\left(\mathrm{r}_{2} / \mathrm{r}_{1}\right)\left(\mathrm{T}_{\infty}-\mathrm{T}_{\mathrm{m}}(\mathrm{x})\right) & \text { eqn. } \mathrm{A} 7 \mathrm{~b} \\
\mathrm{~T}_{3}=\mathrm{T}_{2}(\mathrm{x})+\mathrm{r}_{1} \mathrm{U}_{\mathrm{in}} / \mathrm{k}_{\mathrm{i}, \mathrm{in}} \operatorname{Ln}\left(\mathrm{r}_{3} / \mathrm{r}_{2}\right)\left(\mathrm{T}_{\infty}-\mathrm{T}_{\mathrm{m}}(\mathrm{x})\right) & \text { eqn. } \mathrm{A} 7 \mathrm{c}
\end{array}
$$

The above equations apply to both the hot and cold pipe. The temperature of the fluid entering the cold pipe is found by calculating the temperature of fluid exiting the hot pipe $\left(T_{m}(L)\right.$, using $T_{m}(0)$ as the temperature of the fluid entering the hot pipe) and calculating the temperature of the fluid exiting the heat exchanger by assuming an amount of energy 
equal to $\mathrm{E}_{\mathrm{HX}}$ is deposited in the heat exchanger. The temperature of the fluid entering the cold pipe, $\mathrm{T}_{\mathrm{n}}(0)$, is then:

$$
\mathrm{T}_{\mathrm{n}}(0)=\mathrm{T}_{\mathrm{m}}(\mathrm{L})+\mathrm{E}_{\mathrm{HX}} / \mathrm{mC}_{\mathrm{p}}
$$

When energy is given up by the fluid in the heat exchanger the value of $\mathrm{E}_{\mathrm{HX}}$ is negative.

\section{Reference}

Rainville, E.D. and Bedient, P.E., Elementary Differential Equations, Sixth Edition, Macmillan Publishing Company, Inc., New York. 


\section{Appendix B. Thermal Analysis of the Annular Heat Transport Design}

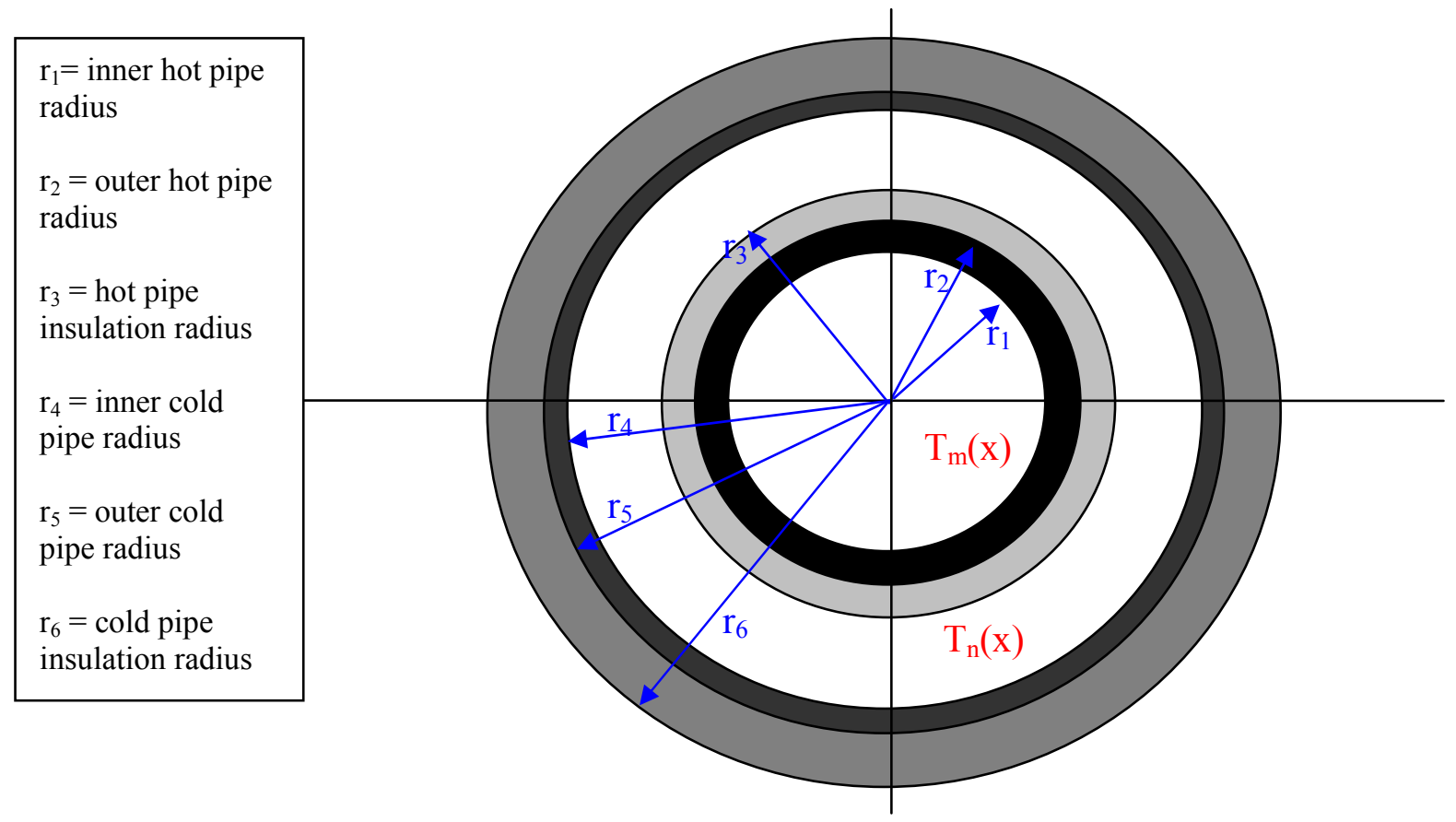

The figure above represents a cross section of a heat transport pipe of annular design. The hot fluid flows through the center of the pipe and has a temperature profile described by $T_{m}(x)$. The cold fluid flows in the opposite direction through the annulus and has a temperature profile given by $\mathrm{T}_{\mathrm{n}}(\mathrm{x})$. The mass flow rate is assumed to be equal but opposite in hot and cold legs of this design. The following analysis is performed on a differential length of the above cross section.

Inner (Hot) Pipe Energy Balance

The change in the mean fluid temperature, $\mathrm{T}_{\mathrm{m}}(\mathrm{x})$, is equal to the energy transferred to the "cold" fluid at a mean temperature of $\mathrm{T}_{\mathrm{n}}(\mathrm{x})$.

$$
\mathrm{m}_{\text {in }} \mathrm{C}_{\mathrm{p}} \mathrm{dT}_{\mathrm{m}}(\mathrm{x})=2 \pi \mathrm{r}_{1} \mathrm{U}_{\mathrm{in}}\left(\mathrm{T}_{\mathrm{n}}(\mathrm{x})-\mathrm{T}_{\mathrm{m}}(\mathrm{x})\right) \mathrm{dx} \quad \text { eqn. B1a }
$$

where

$\mathrm{m}_{\text {in }}=$ mass flow rate in inner, hot pipe

$\mathrm{T}_{\mathrm{m}}(\mathrm{x})=$ mean temperature of the hot fluid at $\mathrm{x}=\mathrm{x}$

$\mathrm{T}_{\mathrm{n}}(\mathrm{x})=$ mean temperature of the cold fluid at $\mathrm{x}=\mathrm{x}$

$\mathrm{U}_{\text {in }}=$ overall heat transfer coefficient on the inner pipe and insulation system defined at $r_{1}$

$\mathrm{C}_{\mathrm{p}}=$ heat capacity

Rearranging, eqn. B1a, may be shown to be: 
or

$$
\mathrm{dT}_{\mathrm{m}}(\mathrm{x}) / \mathrm{dx}=2 \pi \mathrm{r}_{1} \mathrm{U}_{\mathrm{in}} /\left(\mathrm{mC}_{\mathrm{p}}\right)\left(\mathrm{T}_{\mathrm{n}}(\mathrm{x})-\mathrm{T}_{\mathrm{m}}(\mathrm{x})\right) \quad \text { eqn. } \mathrm{B} 1 \mathrm{~b}
$$

where

$$
\mathrm{T}_{\mathrm{n}}(\mathrm{x})=\mathrm{C}_{1} \mathrm{dT}_{\mathrm{m}}(\mathrm{x}) / \mathrm{dx}+\mathrm{T}_{\mathrm{m}}(\mathrm{x})
$$

eqn. B1c

$$
\mathrm{C}_{1}=\mathrm{mC}_{\mathrm{p}} /\left(2 \pi \mathrm{r}_{1} \mathrm{U}_{\mathrm{in}}\right)
$$

Annulus (outer pipe) Energy Balance

The change in the mean fluid temperature of the fluid in the annulus, $T_{n}(x)$, is equal to the difference in the heat transferred from the inner, hot pipe and the heat lost to the environment. Therefore,

$$
\mathrm{m}_{\text {out }} \mathrm{C}_{\mathrm{p}} \mathrm{dT}_{\mathrm{n}}(\mathrm{x})=\mathrm{q}_{\text {out }}-\mathrm{q}_{\text {in }} \quad \text { eqn. } \mathrm{B} 2 \mathrm{a}
$$

or

$$
\mathrm{m}_{\text {out }} \mathrm{C}_{\mathrm{p}} \mathrm{dT}_{\mathrm{n}}(\mathrm{x})=\left(2 \pi \mathrm{r}_{4} \mathrm{U}_{\text {out }}\left(\mathrm{T}_{\infty}-\mathrm{T}_{\mathrm{n}}(\mathrm{x})\right)-2 \pi \mathrm{r}_{1} \mathrm{U}_{\text {in }}\left(\mathrm{T}_{\mathrm{n}}(\mathrm{x})-\mathrm{T}_{\mathrm{m}}(\mathrm{x})\right)\right) \mathrm{dx} \quad \text { eqn. } \mathrm{B} 2 \mathrm{~b}
$$

where

$\mathrm{m}_{\text {out }}=$ mass flow in the annulus - in this case $m_{\text {out }}=-m_{\text {in }}$

$\mathrm{U}_{\text {out }}=$ overall heat transfer coefficient of the outer pipe/insulation system

$\mathrm{T}_{\infty}=$ air temperature in contact with the heat transport system

Eqn. B2b, after rearranging, may be shown to be:

where

$$
\mathrm{C}_{2} \mathrm{dT}_{\mathrm{n}}(\mathrm{x}) / \mathrm{dx}=\mathrm{C}_{3}-\mathrm{C}_{5} \mathrm{~T}_{\mathrm{n}}(\mathrm{x})+\mathrm{C}_{6} \mathrm{~T}_{\mathrm{m}}(\mathrm{x}) \quad \text { eqn. } \mathrm{B} 2 \mathrm{c}
$$

$$
\begin{aligned}
& \mathrm{C}_{2}=\mathrm{m}_{\text {out }} \mathrm{C}_{\mathrm{p}} / 2 \pi \\
& \mathrm{C}_{3}=\mathrm{r}_{4} \mathrm{U}_{\text {out }} \mathrm{T}_{\infty} \\
& \mathrm{C}_{5}=\mathrm{r}_{1} \mathrm{U}_{\text {in }}+\mathrm{r}_{4} \mathrm{U}_{\text {out }} \\
& \mathrm{C}_{6}=\mathrm{r}_{1} \mathrm{U}_{\text {in }}
\end{aligned}
$$

Using eqn. B1c and the derivative of eqn. B1c, specifically:

$$
\mathrm{dT}_{\mathrm{n}}(\mathrm{x}) / \mathrm{dx}=\mathrm{C}_{1}\left(\mathrm{~d}^{2} \mathrm{~T}_{\mathrm{m}}(\mathrm{x}) / \mathrm{dx}^{2}\right)+\mathrm{dT}_{\mathrm{m}}(\mathrm{x}) / \mathrm{dx}
$$

eqn. B3a

and substituting into eqn. B2c

$\mathrm{C}_{2}\left(\mathrm{C}_{1}\left(\mathrm{~d}^{2} \mathrm{~T}_{\mathrm{m}}(\mathrm{x}) / \mathrm{dx}^{2}\right)+\mathrm{dT} \mathrm{m}(\mathrm{x}) / \mathrm{dx}\right)=\mathrm{C}_{3}-\mathrm{C}_{5}\left(\mathrm{C}_{1} \mathrm{dT}_{\mathrm{m}}(\mathrm{x}) / \mathrm{dx}+\mathrm{T}_{\mathrm{m}}(\mathrm{x})\right)+\mathrm{C}_{6} \mathrm{~T}_{\mathrm{m}}(\mathrm{x})$

or

$\mathrm{C}_{1} \mathrm{C}_{2}\left(\mathrm{~d}^{2} \mathrm{~T}_{\mathrm{m}}(\mathrm{x}) / \mathrm{dx} \mathrm{x}^{2}\right)+\left(\mathrm{C}_{2}+\mathrm{C}_{5} \mathrm{C}_{1}\right) \mathrm{dT}_{\mathrm{m}}(\mathrm{x}) / \mathrm{dx}+\left(\mathrm{C}_{5}-\mathrm{C}_{6}\right) \mathrm{T}_{\mathrm{m}}(\mathrm{x})=\mathrm{C}_{3} \quad$ eqn. B3b

If we let:

$\mathrm{A}=\mathrm{C}_{1} \mathrm{C}_{2} \quad \mathrm{~B}=\mathrm{C}_{2}+\mathrm{C}_{5} \mathrm{C}_{1} \quad \mathrm{C}=\mathrm{C}_{5}-\mathrm{C}_{6}$ 
Then we have:

$$
\mathrm{AT}_{\mathrm{m}}{ }^{\prime}+\mathrm{BT}_{\mathrm{m}}{ }^{\prime}+\mathrm{CT}_{\mathrm{m}}=\mathrm{C}_{3} \quad \text { eqn. } \mathrm{B} 3 \mathrm{c}
$$

The particular solution to this differential equation is:

$$
\mathrm{T}_{\mathrm{m}}(\mathrm{x})_{\text {part. }}=\mathrm{C} / \mathrm{C}_{3} \quad \text { eqn. } \mathrm{B} 4 \mathrm{a}
$$

Then we must solve the complimentary differential equation:

$$
\mathrm{AT}_{\mathrm{m}}{ }^{\prime}+\mathrm{BT}_{\mathrm{m}}{ }^{\prime}+\mathrm{CT}_{\mathrm{m}}=0
$$

The solution to which is simply [Rainville, et.al, 1981]:

$$
\mathrm{T}_{\mathrm{m}}(\mathrm{x})_{\text {compl. }}=\mathrm{G}_{1} \mathrm{e}^{-\mathrm{Mx}}+\mathrm{G}_{2} \mathrm{e}^{-\mathrm{Nx}}
$$

where

$$
\begin{aligned}
& M=\left(B-\sqrt{ }\left(B^{2}-4 A C\right)\right) / 2 A \\
& N=\left(B+\left(B^{2}-4 A C\right)\right) / 2 A \\
& G_{1} \& G_{2} \text { are constants that are determined from the boundary conditions }
\end{aligned}
$$

Combining the particular and complimentary solution the final solution is:

$$
\mathrm{T}_{\mathrm{m}}(\mathrm{x})=\mathrm{G}_{1} \mathrm{e}^{-\mathrm{Mx}}+\mathrm{G}_{2} \mathrm{e}^{-\mathrm{Nx}}+\mathrm{C} / \mathrm{C}_{3}
$$

eqn. B4b

Using eqn. $\mathrm{B} 4 \mathrm{~b}$, the expression for $\mathrm{T}_{\mathrm{n}}(\mathrm{x})$ from eqn. $\mathrm{B} 1 \mathrm{c}$ is then:

$$
\mathrm{T}_{\mathrm{n}}(\mathrm{x})=\mathrm{G}_{1}\left(1-\mathrm{C}_{1} \mathrm{M}\right) \mathrm{e}^{-\mathrm{Mx}}+\mathrm{G}_{2}\left(1-\mathrm{C}_{1} \mathrm{~N}\right) \mathrm{e}^{-\mathrm{Nx}}+\mathrm{C}^{-\mathrm{C}_{3}} \quad \text { eqn. } \mathrm{B} 4 \mathrm{c}
$$

\section{$\underline{\text { Boundary Conditions }}$}

At $x=0$ the temperature is assumed to be equal to the inlet loop temperature or $T_{m}(0)=$ $\mathrm{T}_{\mathrm{m} \text {,in. }}$ So from eqn. B4b:

$$
\mathrm{T}_{\mathrm{m}, \mathrm{in}}=\mathrm{G}_{1} \mathrm{e}^{-\mathrm{M}(0)}+\mathrm{G}_{2} \mathrm{e}^{-\mathrm{N}(0)}+\mathrm{C} / \mathrm{C}_{3}
$$

so

$$
\mathrm{G}_{1}=\mathrm{T}_{\mathrm{m}, \mathrm{in}}-\mathrm{G}_{2}-\mathrm{C} / \mathrm{C}_{3}
$$

At $x=L$, the temperature on the annulus fluid is given by:

$$
\mathrm{T}_{\mathrm{n}}(\mathrm{L})=-\mathrm{E}_{\mathrm{HX}} / \mathrm{m}_{\mathrm{in}} \mathrm{C}_{\mathrm{p}}+\mathrm{T}_{\mathrm{m}}(\mathrm{L})
$$

where 


$$
\mathrm{E}_{\mathrm{HX}}=\text { the temperature drop across the process heat exchanger }
$$

Also

$$
\begin{array}{ll}
T_{m}(L)=G_{1} e^{-M L}+G_{2} e^{-N L}+C / C_{3} & \text { eqn. B5c } \\
T_{n}(L)=G_{1}\left(1-C_{1} M\right) e^{-M L}+G_{2}\left(1-C_{1} N\right) e^{-N L}+C / C_{3} & \text { eqn. B5d }
\end{array}
$$

Substituting eqn. B5c into eqn. B5b, equating to eqn. B5d and using eqn. B5a one can solve for $\mathrm{G}_{2}$. One finds that $\mathrm{G}_{2}$ is:

$$
\mathrm{G}_{2}=\left(\mathrm{E}_{\mathrm{HX}} / \mathrm{C}_{1} \mathrm{~m}_{\mathrm{in}} \mathrm{C}_{\mathrm{p}}-\left(\mathrm{T}_{\mathrm{m}, \mathrm{in}}-\mathrm{C} / \mathrm{C}_{3}\right) \mathrm{Me}^{-\mathrm{ML}}\right) /\left(\mathrm{Ne}^{-\mathrm{NL}}-\mathrm{Me}^{-\mathrm{ML}}\right) \quad \text { eqn. } \mathrm{B} 5 \mathrm{e}
$$

All constants are now determined and the mean temperature profile of the hot and cold fluids can be calculated as well as the temperature at $r_{1}, r_{2}, r_{3}, r_{4}, r_{5}$ and $r_{6}$, i.e. $T_{1}, T_{2}, T_{3}$, $\mathrm{T}_{4}, \mathrm{~T}_{5}, \mathrm{~T}_{6}$, respectively, from:

$$
\begin{array}{lr}
\mathrm{T}_{1}=\mathrm{T}_{\mathrm{m}}(\mathrm{x})+\mathrm{U}_{\mathrm{in}} / \mathrm{h}_{1}\left(\mathrm{~T}_{\mathrm{n}}(\mathrm{x})-\mathrm{T}_{\mathrm{m}}(\mathrm{x})\right) & \text { eqn. B6a } \\
\mathrm{T}_{2}=\mathrm{T}_{1}(\mathrm{x})+\mathrm{r}_{1} \mathrm{U}_{\mathrm{in}} / \mathrm{k}_{\mathrm{p}, \mathrm{in}} \operatorname{Ln}\left(\mathrm{r}_{2} / \mathrm{r}_{1}\right)\left(\mathrm{T}_{\mathrm{n}}(\mathrm{x})-\mathrm{T}_{\mathrm{m}}(\mathrm{x})\right) & \text { eqn. B6b } \\
\mathrm{T}_{3}=\mathrm{T}_{2}(\mathrm{x})+\mathrm{r}_{1} \mathrm{U}_{\mathrm{in}} / \mathrm{k}_{\mathrm{i}, \mathrm{in}} \operatorname{Ln}\left(\mathrm{r}_{3} / \mathrm{r}_{2}\right)\left(\mathrm{T}_{\mathrm{n}}(\mathrm{x})-\mathrm{T}_{\mathrm{m}}(\mathrm{x})\right) & \text { eqn. B6c } \\
\mathrm{T}_{4}=\mathrm{T}_{\mathrm{n}}(\mathrm{x})+\mathrm{U}_{\text {out }} / \mathrm{h}_{4}\left(\mathrm{~T}_{\infty}-\mathrm{T}_{\mathrm{n}}(\mathrm{x})\right) & \text { eqn. B6d } \\
\mathrm{T}_{5}=\mathrm{T}_{4}(\mathrm{x})+\mathrm{r}_{4} \mathrm{U}_{\text {out }} / \mathrm{k}_{\mathrm{p}, \text { out }} \operatorname{Ln}\left(\mathrm{r}_{5} / \mathrm{r}_{4}\right)\left(\mathrm{T}_{\infty}-\mathrm{T}_{\mathrm{n}}(\mathrm{x})\right) & \text { eqn. B6e } \\
\mathrm{T}_{6}=\mathrm{T}_{5}(\mathrm{x})+\mathrm{r}_{4} \mathrm{U}_{\text {out }} / \mathrm{k}_{\mathrm{i}, \text { out }} \operatorname{Ln}\left(\mathrm{r}_{6} / \mathrm{r}_{5}\right)\left(\mathrm{T}_{\infty}-\mathrm{T}_{\mathrm{n}}(\mathrm{x})\right) & \text { eqn. B6f }
\end{array}
$$

where

$$
\begin{aligned}
& \mathrm{h}_{1}=\text { heat transfer coefficient between the hot fluid and the inner piper wall } \\
& \mathrm{k}_{\mathrm{p}, \mathrm{in}}=\text { thermal conductivity of the inner pipe material } \\
& \mathrm{k}_{\mathrm{i}, \mathrm{in}}=\text { thermal conductivity of the insulation surrounding the inner pipe } \\
& \mathrm{h}_{4}=\text { heat transfer coefficient between the cold fluid and the annulus wall } \\
& \mathrm{k}_{\mathrm{p}, \text { out }}=\text { thermal conductivity of the outer pipe material } \\
& \mathrm{k}_{\mathrm{i}, \text { in }}=\text { thermal conductivity of the insulation surrounding the outer pipe }
\end{aligned}
$$

\section{Reference}

Rainville, E.D. and Bedient, P.E., Elementary Differential Equations, Sixth Edition, Macmillan Publishing Company, Inc., New York, 1981. 


\section{Appendix C. Parameters Used in the Thermal Analysis}

\begin{tabular}{|c|c|c|c|c|c|c|c|c|c|c|c|c|}
\hline \multirow{3}{*}{\begin{tabular}{l|} 
Pipe \\
Configuration
\end{tabular}} & \multicolumn{5}{|c|}{ Separate hot/cold leg } & \multicolumn{5}{|c|}{ Annulus Š pipe/insulation } & \multicolumn{2}{|c|}{$\begin{array}{c}\text { Annulus Š } \\
\text { insulation/pipe }\end{array}$} \\
\hline & \multicolumn{2}{|c|}{$\mathrm{He}, 2 \mathrm{MPa}$} & \multirow{2}{*}{$\begin{array}{c}\mathrm{He}, 7 \\
\mathrm{MPa}\end{array}$} & \multicolumn{2}{|c|}{ Flinak } & \multicolumn{2}{|c|}{$\mathrm{He}, 2 \mathrm{MPa}$} & \multirow{2}{*}{$\begin{array}{c}\mathrm{He}, 7 \\
\mathrm{MPa}\end{array}$} & \multicolumn{2}{|c|}{ Flinak } & \multirow{2}{*}{$\begin{array}{c}\mathrm{He}, 2 \\
\mathrm{MPa}\end{array}$} & \multirow{2}{*}{$\begin{array}{c}\text { Flinak } \\
500\end{array}$} \\
\hline & 90 & 500 & & 90 & 500 & 90 & 500 & & 90 & 500 & & \\
\hline $\begin{array}{l}\text { Mass flow rate, } \\
\mathrm{m}, \mathrm{kg} / \mathrm{s}\end{array}$ & 24.1 & 24.1 & 24.1 & 133 & 133 & 24.1 & 24.1 & 24.1 & 133 & 133 & 24.1 & 133 \\
\hline $\begin{array}{l}\text { Heat Capacity, } \\
\mathrm{C}_{\mathrm{p}}, \mathrm{J} / \mathrm{kg} \cdot{ }^{\circ} \mathrm{C}\end{array}$ & 5193 & 5193 & 5193 & 1905 & 1905 & 5193 & 5193 & 5193 & 1905 & 1905 & 5193 & 1905 \\
\hline \multicolumn{13}{|c|}{ Hot Leg } \\
\hline $\mathrm{r}_{1}, \mathrm{~m}$ & 0.211 & 0.295 & 0.164 & 0.065 & 0.099 & 0.211 & 0.295 & 0.164 & 0.065 & 0.099 & 0.295 & 0.099 \\
\hline $\mathrm{r}_{2}, \mathrm{~m}$ & 0.262 & 0.366 & 0.203 & 0.079 & 0.121 & 0.262 & 0.366 & 0.203 & 0.079 & 0.121 & 0.301 & 0.100 \\
\hline $\mathrm{r}_{3}, \mathrm{~m}$ & 0.357 & 0.468 & 0.291 & 0.147 & 0.197 & 0.267 & 0.371 & 0.209 & 0.080 & 0.121 & 0.006 & 0.121 \\
\hline $\begin{array}{r}\begin{array}{r}\text { Insulation } \\
\text { thickness, } \mathrm{m}\end{array} \\
\end{array}$ & 0.095 & 0.102 & 0.088 & 0.068 & 0.076 & 0.006 & 0.006 & 0.006 & 0.001 & 0.001 & 0.373 & 0.001 \\
\hline $\begin{array}{r}\text { Fluid density, } \\
\mathrm{kg} / \mathrm{m}^{3}\end{array}$ & 0.86 & 0.86 & 2.98 & 1880 & 1880 & 0.86 & 0.86 & 2.98 & 1880 & 1880 & 0.86 & 1880 \\
\hline $\begin{array}{r}\text { Fluid velocity, } \\
\mathrm{m} / \mathrm{s}\end{array}$ & 201.4 & 103 & 95.7 & 5.3 & 2.3 & 201.4 & 103.0 & 95.7 & 5.3 & 2.3 & 103.0 & 2.3 \\
\hline $\begin{array}{r}\text { Fluid viscosity, } \\
\mathrm{kg} / \mathrm{m} \cdot \mathrm{s}\end{array}$ & $4.83 \mathrm{E}-5$ & $4.83 \mathrm{E}-5$ & $4.83 \mathrm{E}-5$ & $1.62 \mathrm{E}-3$ & $1.62 \mathrm{E}-3$ & $4.83 \mathrm{E}-5$ & $4.83 \mathrm{E}-5$ & $4.83 \mathrm{E}-5$ & $1.62 \mathrm{E}-3$ & $1.62 \mathrm{E}-3$ & $4.83 \mathrm{E}-5$ & $1.62 \mathrm{E}-3$ \\
\hline $\begin{array}{r}\text { Fluid thermal } \\
\text { conductivity, } \\
\mathrm{W} / \mathrm{m}^{\circ}{ }^{\circ} \mathrm{C}\end{array}$ & 0.382 & 0.382 & 0.382 & 0.8 & 0.8 & 0.382 & 0.382 & 0.382 & 0.8 & 0.8 & 0.382 & 0.8 \\
\hline \multicolumn{13}{|c|}{ Cold Leg } \\
\hline $\mathrm{r}_{4}, \mathrm{~m}$ & 0.194 & 0.27 & 0.152 & 0.065 & 0.098 & 0.37 & 0.500 & 0.280 & 0.120 & 0.160 & 0.500 & 0.160 \\
\hline $\mathrm{r}_{5}, \mathrm{~m}$ & 0.240 & 0.335 & 0.188 & 0.071 & 0.108 & 0.459 & 0.620 & 0.347 & 0.149 & 0.198 & 0.620 & 0.198 \\
\hline $\mathrm{r}_{6}, \mathrm{~m}$ & 0.286 & 0.384 & 0.232 & 0.122 & 0.165 & 0.512 & 0.671 & 0.397 & 0.210 & 0.263 & 0.671 & 0.263 \\
\hline $\begin{array}{r}\text { Insulation } \\
\text { thickness, } m\end{array}$ & 0.046 & 0.49 & 0.044 & 0.051 & 0.057 & 0.053 & 0.051 & 0.050 & 0.061 & 0.065 & 0.051 & 0.065 \\
\hline $\begin{array}{r}\text { Fluid density, } \\
\mathrm{kg} / \mathrm{m}^{3}\end{array}$ & 1.33 & 1.35 & 4.61 & 2099 & 2099 & 1.33 & 1.35 & 4.61 & 2099 & 2099 & 1.24 & 2099 \\
\hline $\begin{array}{r}\text { Fluid velocity, } \\
\mathrm{m} / \mathrm{s}\end{array}$ & 154.0 & 78.2 & 72.0 & 4.8 & 2.1 & 88.2 & 50.7 & 47.9 & 2.50 & 1.9 & 55.7 & 1.9 \\
\hline $\begin{array}{r}\text { Fluid viscosity, } \\
\mathrm{kg} / \mathrm{m} \cdot \mathrm{s}\end{array}$ & $3.58 \mathrm{e}-5$ & $3.55 \mathrm{E}-5$ & $3.58 \mathrm{e}-5$ & $3.63 \mathrm{E}-3$ & $3.67 \mathrm{E}-3$ & $3.58 \mathrm{E}-5$ & $3.75 \mathrm{E}-5$ & $3.60 \mathrm{E}-5$ & $3.67 \mathrm{E}-3$ & $3.67 \mathrm{E}-3$ & $3.75 \mathrm{E}-5$ & $4.11 \mathrm{E}-3$ \\
\hline $\begin{array}{r}\text { Fluid thermal } \\
\text { conductivity, } \\
\mathrm{W} / \mathrm{m} \cdot{ }^{\circ} \mathrm{C}\end{array}$ & 0.289 & 0.286 & 0.290 & 0.8 & 0.8 & 0.289 & 0.289 & 0.290 & 0.8 & 0.8 & 0.303 & 0.8 \\
\hline $\begin{array}{l}\text { Pipe Material } \\
\text { Thermal } \\
\text { Conductivity, } \\
\mathrm{W} / \mathrm{m}^{\circ}{ }^{\circ} \mathrm{C}\end{array}$ & 25 & 25 & 25 & 25 & 25 & 25 & 25 & 25 & 25 & 25 & 25 & 25 \\
\hline $\begin{array}{l}\text { Insulation } \\
\text { Thermal } \\
\text { Conductivity, } \\
\mathrm{W} / \mathrm{m}^{\circ}{ }^{\circ} \mathrm{C}\end{array}$ & 0.1 & 0.1 & 0.1 & 0.1 & 0.1 & 0.1 & 0.1 & 0.1 & 0.1 & 0.1 & 0.1 & 0.1 \\
\hline
\end{tabular}

